\title{
Determinação do grupo filogenético e pesquisa dos genes de resistência em Escherichia coli provenientes de amostras de alimentos, ambientais e clínicas.
}

\author{
Patrícia Pereira de Souza
}

Dissertação apresentada ao programa de Pós-Graduação em Saúde de Pública para obtenção do título de Mestre em Saúde Pública

Área de Concentração: Serviços de Saúde Pública

Orientador: Prof (a). Associada Dr (a). Maria Helena Matté 


\title{
Universidade de São Paulo \\ Faculdade de Saúde Pública
}

\section{Determinação do grupo filogenético e pesquisa dos genes de resistência em Escherichia coli provenientes de amostras de alimentos, ambientais e clínicas.}

\author{
Patrícia Pereira de Souza
}

Dissertação apresentada ao Programa de Pós-Graduação em Saúde de Pública para obtenção do título de Mestre em Saúde Pública.

Área de Concentração: Serviços de Saúde Pública Orientador: Prof (a). Associada Dr (a). Maria Helena Matté

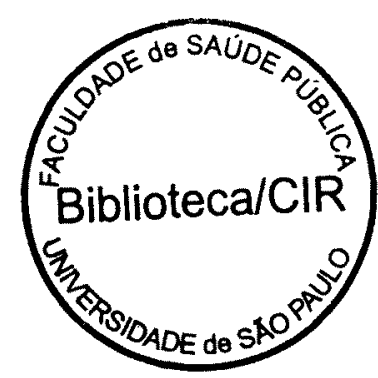

São Paulo

2012 
É expressamente proibida a comercialização deste documento tanto na sua forma impressa como eletrônica. Sua reprodução total ou parcial é permitida exclusivamente para fins acadêmicos e científicos, desde que na reprodução figure a identificação do autor, título, instituição e ano de dissertação. 


\section{DEDICATÓRIA}

Dedico este trabalho aos meus pais, José e Claudete por todo amor e carinho. 
O pensamento escolhe. A ação realiza. O homem conduz o barco da vida com os remos do desejo e a vida conduz o homem ao porto que ele aspira a chegar. Eis porque, segundo as Leis que nos regem, "a cada um será dado segundo suas próprias obras" (Emmanuel) 


\section{AGRADECIMENTOS}

Agradeço primeiramente a Deus, por essa oportunidade concedida em minha vida, aos meus pais que sempre me incentivaram a estudar e por todo o apoio nessa trajetória.

À minha orientadora Maria Helena Matté por ter me aceitado no laboratório, desde 2009 na participação do projeto. Por ter se empenhado em conseguir uma bolsa de estudo para que eu pudesse iniciar o mestrado e acima de tudo pela sua compreensão, orientação e ajuda nos momentos de desespero ocorridos durante a realização deste trabalho.

À especialista de laboratório Milena Dropa por todas as explicações, correções e dicas, as quais auxiliaram muito para realização deste trabalho.

À técnica de laboratório Miriam Lopes sempre tão disposta a ajudar-me, pelo seu olhar crítico na "construção" de tabelas e pelos cafés oferecidos durante esses anos.

Aos integrantes da banca, Dra. Ana Cristina Gales e Dra. Maria Inês Zanoli Sato pelas sugestões e correções da dissertação.

À profa Irma Nelly Gutierrez Rivera pela disponibilização de uso de algumas cepas que foram estudadas.

Livia, Danielle e Ronalda pelas dicas, sugestões e pela troca de experiências. À Flávia, que nos momentos finais da realização deste trabalho também me ajudou. 
Às minhas amigas e companheiras de laboratório, Kelvilin, Elisabeth, Camila, Licia, Miriam, Luisa, Rafaela, Helena, Cintia e Cristiane pelos momentos de descontração, almoços, pelos conselhos, por ouvirem minhas dúvidas, inseguranças e desabafos e por me ajudarem no momento em que eu mais precisei.

Ao Ricardo pelo apoio, compreensão, dedicação durante os momentos dificeis.

Tatiani e Rose, que mesmo estando longe, sempre me incentivaram e pelo orgulho que sentem por eu ter chegado até aqui.

Ao pessoal da epidemiologia, Delsio Natal, Paulo Urbinatti, Walter Cereti e Ana (da Tisio) pelo incentivo na realização do mestrado.

Ao CNPq pela bolsa de estudo concedida.

A todos que me ajudaram de alguma forma Obrigada!! 


\section{RESUMO}

SOUZA PP. Determinação do grupo filogenético e pesquisa dos genes de resistência em Escherichia coli provenientes de amostras de alimentos, ambientais e clínicas. [Dissertação de mestrado]. São Paulo: Faculdade de Saúde Pública da USP; 2012.

INTRODUÇÃO - Escherichia coli é faz parte da microbiota intestinal de humanos e de animais de sangue quente São os bacilos Gram-negativos mais frequentemente isolados de infecções humanas e tem sido associada à meningite neonatal, sepse, infecções do trato urinário e gastroenterite. OBJETIVO - Determinar o grupo filogenético, identificar o perfil de suscetibilidade a diferentes classes de antimicrobianos e pesquisar os genes de resistência em isolados de $E$. coli provenientes de amostras de alimentos, ambientais e clínicas. MÉTODOS - Foram utilizados 65 isolados, de 1990 a 2006, pertencentes à coleção de cultura do laboratório de Prática de Saúde Pública. Os isolados eram provenientes de queijo minas frescal, água tratada, água mineral, fezes de bovinos sadios, água doce coletada de ambiente pristino e de pacientes atendidos em um hospital universitário. O antibiograma foi realizado pelo método de Disco-Difusão em ágar de acordo com CLSI 2009. A pesquisa dos genes de resistência a beta-lactâmicos foi realizada por meio da PCR. RESULTADOS - Dos 65 isolados de E. coli, 32,30\% (21/65) pertenceram ao grupo filogenético A, 61,53\% (40/65) pertenceram ao grupo B1, $1,53 \%(1 / 65)$ ao grupo B2 e $4,61 \% 93 / 65)$ ao grupo D. Os resultados do antibiograma revelaram que $26,15 \%$ dos isolados foram resistentes a pelo menos um antimicrobiano, mas nenhum gene de resistência foi detectado. CONCLUSÕES - Os 
resultados indicam que o grupo filogenético B1 foi o de maior frequência entre os isolados de $E$. coli de diversas origens. Além disso, a resistência observada mostra que bactérias comensais podem representar uma preocupação para a Saúde Pública uma vez que podem servir como reservatório de genes de resistência para outros microrganismos potencialmente patogênicos.

Descritores: Escherichia coli; Grupo Filogenético; Antibiograma; Genes de Resistência. 


\begin{abstract}
SOUZA PP. Determinação do grupo filogenético e pesquisa dos genes de resistência em Escherichia coli provenientes de amostras de alimentos, ambientais e clínicas / Determination of phylogenetic group and research for resistance genes in Escherichia coli from food, environmental and clinical samples [dissertation]. São Paulo (BR): Faculdade de Saúde Pública da USP; 2012.
\end{abstract}

INTRODUCTION - Escherichia coli is part of the intestinal microbiota of human and warm-blooded animals. It is the Gram-negative bacilli most frequently isolated from human infections and it has been associated with neonatal meningitis, sepsis, urinary tract infections and gastroenteritis. OBJECTIVE - To determine the phylogenetic group, identify the susceptibility profile to different antimicrobial classes and research resistance genes in E. coli isolates from food, environmental and clinical samples. METHODS - Were used 65 isolates, from 1990 to 2006, belonging to the culture collection of the laboratory of Public Health Practice. This isolates originated from fresh cheese, treated water, mineral water, feces of healthy cattle, water collected from pristine environment and patients treated at a university hospital. The antibiogram was performed by disk-diffusion method according to the CLSI 2009. The research for beta-lactam resistance genes was done by PCR. RESULTS - From the 65 E. coli isolates, $32.30 \%$ (21/65) belonged to the phylogenetic group A, $61.53 \%$ (40/65) to group B1, $1.53 \%$ (1/65) to group B2 and $4.61 \%(93 / 65)$ to group D. The antibiogram results revealed that $26.15 \%$ of the isolates were resistant to at least one antimicrobial agent, however, no resistance 
gene was detected. CONCLUSIONS - The results indicate that the phylogenetic group B1 was the most frequent among $E$. coli isolates from various sources. Furthermore, the observed resistance indicates that commensal bacteria may represent a concern to public health since they can serve as a reservoir of resistance genes to other potentially pathogenic microorganisms.

Descriptors: Escherichia coli; Phylogenetic Group; Antibiogram; Resistance Genes. 


\section{ÍNDICE}

1 INTRODUÇÃO .................................................................................... 17

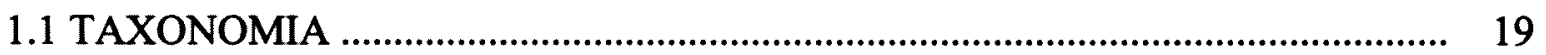

1.2 PATOGENICIDADE ……………......................................................... 20

1.2.1 E. coli Diarreiogênicas ..................................................................................... 21

1.2.1.1 E. coli Enterotoxigênica (ETEC) .................................................................. 22

1.2.1.2 E. coli Enteropatogênica (EPEC) ………................................................... 23

1.2.1.3 E. coli Enterohemorrágica (EHEC) .............................................................. 24

1.2.1.4 E. coli Enteroagregativa (EAEC) ………………….................................... 25

1.2.1.5 E. coli Enteroinvasiva (EIEC) .................................................................. 26

1.2.1.6 E. coli Difusamente Aderente (DAEC) ……………....................................... 26

1.3 GRUPO FILOGENÉTICO.............................................................................. 27

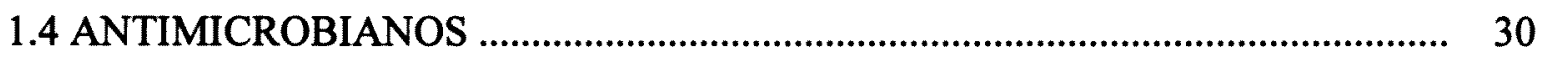

1.5 RESISTÊNCIA BACTERIANA ……........................................................ 30

1.5.1 Antimicrobianos $\beta$-Lactâmicos …………………………………………….... 33

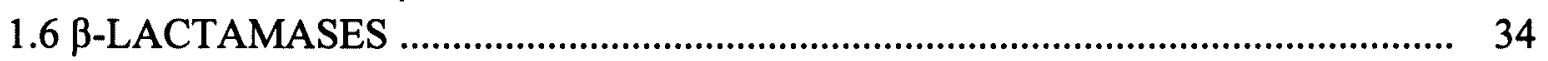

1.6.1 $\beta$-Lactamases de Espectro Estendido - ESBL …………………………………...... 37

1.6.2 Metalo- $\beta$-Lactamases - MBL …………………………..................................... 38

$1.6 .3 \beta$-Lactamases AmpC ..................................................................................... $\quad 40$

1.7 RESISTÊNCIA EM E. coli ......................................................................... 42

1.7.1 Resistência aos Antimicrobianos e Presença de Genes .......................................... 42

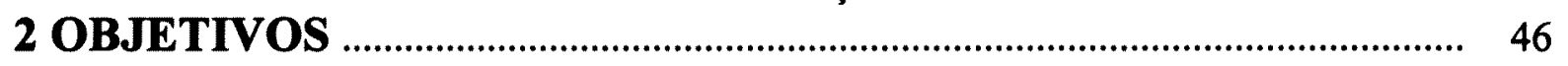

2.1 OBJETIVO GERAL ............................................................................... 46

2.2 OBJETIVOS ESPECÍFICOS ....................................................................... 46

3 MATERIAL E MÉTODOS ……................................................................ 47

3.1 REISOLAMENTO E IDENTIFICAÇÃO DAS COLÔNIAS ................................... 47

3.2 EXTRAÇÃO DO DNA TOTAL ................................................................... 48

3.3 IDENTIFICAÇÃO DO GRUPO FILOGENÉTICO ……………………………...... 49

3.4 TESTE DE SENSIBILIDADE AOS ANTIMICROBIANOS ............................... 50

3.4.1 Identificação Fenotípica para Produção de ESBL ................................................ 52

3.4.2 Identificação Fenotípica para Produção de AmpC .............................................. 52

3.4.3 Identificação Fenotipica para Produção de MBL ………………………………... 53

3.5 IDENTIFICAÇÃO DOS GENES DE RESISTÊNCIA ............................................ 53

3.5.1 Deteç̧ão dos Genes Codificadores de AmpC ....................................................... 53

3.5.2 Deteç̧ão dos Genes Codificadores de MBL ……………................................... 55

3.6 ELETROFORESE EM GEL DE AGAROSE ..................................................... 56

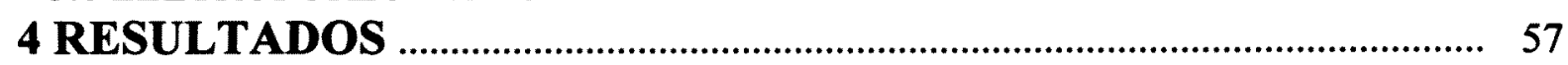

4.1 GRUPO FILOGENÉTICO ........................................................................ 57

4.2 ANÁLISE FENOTÍPICA DE SENSIBILIDADE AOS ANTIMICROBIANOS, PRODUÇÃO DE ENZIMAS $\beta$-LACTAMASES E DETECÇÃO DE GENES 


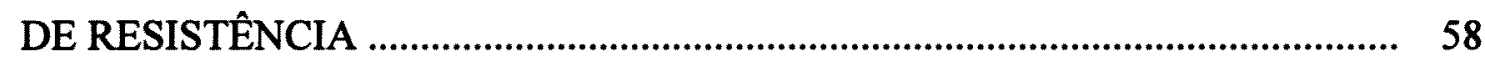

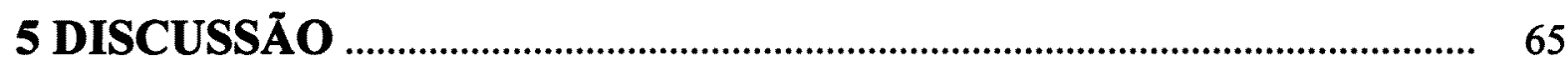

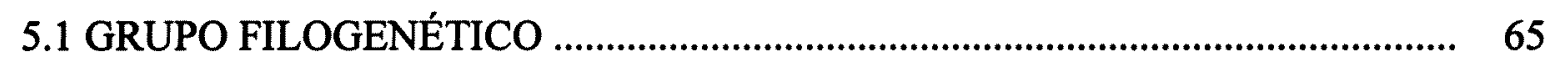

5.2 TESTE DE SENSIBILIDADE AOS ANTIMICROBIANOS..................................... 66

5.3 $\beta$-LACTAMASES (ESBL, AmpC e MBL) ............................................................. 68

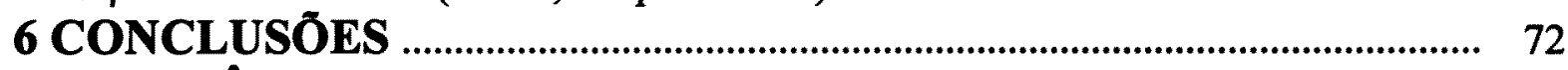

7 REFERENCIAS ….................................................................................. 73 


\section{Lista de Quadros}

Quadro 1- Esquema de classificação para $\beta$-lactamases

Quadro 2- Relação dos iniciadores utilizados para determinação do grupo filogenético

Quadro 3- Lista de antimicrobianos e respectivos valores dos halos em mm

Quadro 4- Iniciadores utilizados para pesquisa de genes AmpC

Quadro 5- Iniciadores utilizados para pesquisa de genes MBL

Quadro 6- Resultados do Antibiograma dos 65 isolados de E. coli de acordo com $o$ ano de isolamento e origem

\section{Lista de Figuras}

Figura 1- Representação dos grupos filogenéticos utilizando os iniciadores para os genes chuA, yjaA e fragmentos de DNA TSPE4.C2

Figura 2- Deteç̧ão fenotípica da produção de AmpC utilizando a técnica de discos combinados .Discos contendo $30 \mu \mathrm{g}$ do antibiótico cefotetan (CTT) colocados a uma distância de 20 a $30 \mathrm{~mm}$ do disco contendo o inibidor ácido fenilborônico (BA) 


\section{Lista de Tabelas}

Tabela 1- Descrição dos isolados utilizados no presente estudo.

Tabela 2- Distribuição do grupo filogenético em isolados

de $E$. coli provenientes de diferentes tipos de amostras

Tabela 3- Número e porcentagem de isolados de acordo com o perfil de suscetibilidade aos antimicrobianos 


\section{INTRODUÇÃO}

As enterobactérias são bacilos Gram negativos pertencentes à família Enterobacteriaceae. Possuem grande importância microbiológica e médica devido às infecções causadas, patogenicidade e ao surgimento de bactérias multirresistentes aos antimicrobianos utilizados na terapêutica (SADER et al., 2001; FARMER III; BOATWRIGHT; JANDA, 2007).

A maioria dos gêneros e espécies pertencentes à família Enterobacteriaceae apresentam as seguintes propriedades: são bacilos Gram negativos retos, não formam esporos, possuem motilidade peritriquia ou são imóveis, desenvolvem-se em peptona ou extrato de carne sem a adição de suplemento ou cloreto de sódio, como também em ágar MacConkey, são cultivadas em aerobiose ou anaerobiose, fermentam glicose e outros açúcares, reduzem nitrato a nitrito (FARMER III; BOATWRIGHT; JANDA, 2007).

Enterobacteriaceae estão dispersas na natureza e podem ser encontradas em plantas, solo, água e microbiota normal do trato intestinal dos seres humanos e animais. Podem estar associadas com infecções comunitárias e hospitalares, oportunistas ou não. Muitas espécies são causadoras de infecções urinárias, intestinais, pneumonias, feridas cirúrgicas, sepse e meningites (FARMER III; BOATWRIGHT; JANDA, 2007), dentre elas destaca-se Escherichia coli.

E. coli faz parte da microbiota do intestino humano e de animais de sangue quente. Coloniza o trato gastrointestinal logo nas primeiras horas de vida do recém- 
nascido (KAPER et al., 2004) usualmente permanece colonizadora, confinada ao lúmen intestinal, entretanto em indivíduos debilitados ou imunocomprometidos, ou ainda quando as barreiras do trato gastrointestinal são violadas, mesmo as espécies não patogênicas podem causar infecções (NATARO e KAPER, 1998).

$E$. coli é a bactéria mais comumente isolada nos laboratórios clínicos e está associada com uma variedade de doenças, incluindo meningite neonatal, gastroenterite e infecção do trato urinário (ITU) (KAPER et al., 2004).

Por ser encontrada normalmente nas fezes é usada como indicador de contaminação fecal da água e dos alimentos, Além disso, a presença de uma bactéria de origem fecal pode sinalizar a presença de outras bactérias enteropatogênicas, tais como Salmonella spp e Shigella spp (PEDRO, 2009).

No Brasil, a Agência Nacional de Vigilância Sanitária por meio da Resolução $\operatorname{RDC~}^{\circ} 12$, de 2 de janeiro de 2001, estabelecem os limites de tolerância de $E$. coli e outros microrganismos, em alimentos visando proteção à saúde e à qualidade microbiológica do mesmo (BRASIL, 2001). A portaria 2914 do Ministério da Saúde determina os padrões de potabilidade da água para o consumo humano, na qual $E$. coli deve estar ausente e o Conselho Nacional do Meio Ambiente - CONAMA considera que a saúde e o bem-estar possam ser afetados pela qualidade da água de balneabilidade (recreação de contato primário), quando micorganismos estão presentes, tendo como legislação vigente a resolução 274 de 29 , de novembro de 2000 (MS, 2011; BRASIL, 2000). Para tanto essas três legislações recomendam a pesquisa de coliformes nos produtos a que se referem uma vez que a presença desses 
organismos pode representar risco á saúde dos indivíduos que fizerem uso dos produtos que são objeto dessas três legislações.

\subsection{TAXONOMIA}

Segundo o Bergey's Manual of Systematic Bacteriology (SCHEUTZ e STROCKBINE, 2005) o gênero Escherichia pertence à família Enterobacteriaceae, são bacilos Gram-negativos, possuem motilidade através de flagelos peritríquios ou imóveis. São anaeróbios facultativos, quimiorganotróficos (organismos que utilizam os compostos orgânicos como fonte de energia), fermentadores de lactose e glicose com produção de ácido e gás. São oxidase negativa, catalase positiva, lisina descarboxilase e ornitina positivas, manitol e indol positivos.

O gênero consiste de cinco espécies: $E$. coli, E. hermannii, E. fergusonii, $E$. vulneris e $E$. blatae. As reações bioquímicas auxiliam na diferenciação entre as espécies, visto que $E$. coli difere das demais espécies por apresentar reação positiva para sorbitol (SCHEUTZ e STROCKBINE, 2005)

Cresce muito bem à temperatura de $37^{\circ} \mathrm{C}$ e os valores de $\mathrm{pH}$ para crescimento oscilam entre 5,0 e 9,0 (SCHEUTZ e STROCKBINE, 2005).

Para a diferenciação de membros da família Enterobacteriaceae que fermentam a lactose, são utilizados os meios de cultura ágar MacConkey e o ágar eosina-azul-de-metileno (EMB), os quais são meios seletivos utilizados para isolamento primário. No meio ágar MacConkey as colônias de $E$. coli geralmente crescem com coloração vermelha, lisas, circulares, convexas com margens distintas e 
não viscosas (KONEMAN et al., 2005; BROOKS et al., 2009). As colônias aparecem vermelhas devido à intensa fermentação da glicose, produzindo grande quantidade de ácidos mistos e a precipitação dos sais biliares do ágar que envolve as colônias. Em ágar EMB, as colônias aparecem com um brilho verde metálico (KONEMAN et al., 2005).

\subsection{PATOGENICIDADE}

Diversas linhagens de $E$. coli são patogênicas para o homem e animais. Essas cepas são classificadas de acordo com suas propriedades de virulência (BROOKS et al., 2009).

As categorias que causam infecção intestinal são denominadas de $E$. coli diarreiogênicas, as que ocasionam infecções, tais como meningite e sepsis, são chamadas de $E$. coli Extra-intestinais (EXPEC). Dentro da categoria das EXPEC existem as $E$. coli uropatogênicas (UPEC) as quais são responsáveis pelas infecções do trato urinário (ITU) e as cepas de $E$. coli que causam meningite, as quais são denominadas de MNEC (NATARO e KAPER, 1998; KAPER et al., 2004).

E. coli possui algumas estruturas celulares antigênicas, tais como flagelos, lipopolissacarídios-LPS e cápsulas. Os flagelos são denominados de antígenos $\mathrm{H}$ e as cápsulas, antígenos capsulares ou antígenos $\mathrm{K}$. A molécula do LPS tem o antígeno $\mathrm{O}$ que corresponde ao polissacarídeo da cadeia lateral da molécula (KAPER et al., 2004). A sorotipagem é feita com base na presença dos antígenos, $\mathrm{O}, \mathrm{K} \mathrm{e} \mathrm{H}$, podendo desta forma dividir a espécie em sorogrupos e sorotipos (NATARO e KAPER, 1998). 
Os fatores de virulência em cada linhagem de E.coli são diferentes, entretanto, eles podem ser agrupados em: fatores de colonização, que beneficiam a íntima ligação da bactéria à mucosa intestinal e impedem a remoção da mesma pelo peristaltismo, e a liberação de toxinas, as quais interferem nos processos fisiológicos normais das células do hospedeiro (ROBINS-BROWNE e HARTLAND, 2002).

\subsubsection{E. coli Diarreiogênicas}

Com base na virulência, características clínicas e enterotoxinas as E.coli diarreiogênicas são divididas em seis classes (KAPER et al., 2004):

- E. coli Enterotoxigênica (ETEC)

- E. coli Enteropatogênica (EPEC)

- E. coli Enterohemorrágica (EHEC)

- E. coli Enteroagregativa (EAEC)

- $\quad$. coli Enteroinvasiva (EIEC)

- $E$. coli Difusamente Aderente (DAEC)

A diferenciação dessas cepas é feita através da detecção dos genes que codificam as características de virulência por meio de técnicas moleculares, como a PCR, além de sorotipagem e pesquisa de produção de toxinas (NATARO e KAPER, 1998). 


\subsubsection{E. coli Enterotoxigênica (ETEC)}

ETEC é a principal causa da diarréia aguda em crianças menores de cinco anos de idade em todo o mundo. Além disso, é um importante patógeno em animais (KAPER et al., 2004).

ETEC coloniza a mucosa do intestino delgado e secreta as enterotoxinas termo-labil LT (Heat-labile toxin) e a toxina termo estável ST (Heat-stable toxin), as quais aumentam a secreção intestinal, podendo expressar somente a toxina LT ou somente a ST ou ainda expressar ambas as toxinas (BROOKS et al., 2009).

A toxina LT está intimamente relacionada na estrutura e função com a enterotoxina colérica produzida por Vibrio cholerae. Existem dois principais sorogrupos de LT: LTI e LTII, os quais não apresentam reação cruzada imunologicamente. LTI é expressa por cepas de E.coli patogênicas para humanos e animais. A LTII foi encontrada primeiramente em cepas de E.coli isoladas de animais e raramente em isolados humanos, mas nunca foi associada a doenças em humanos ou animais. A LTI tem duas variantes: LTp (LTp-I) e LTh ( LTh-I), as quais foram inicialmente descobertas de cepas isoladas de suínos e humanos respectivamente (NATARO e KAPER, 1998).

Os genes que codificam LT (elt) estão localizados em plasmídeos que também podem ter o gene codificador de ST e/ou antígenos de fatores de colonização (NATARO e KAPER, 1998). 
A toxina ST divide-se em duas classes: STa e STb Ambas diferem na estrutura e no mecanismo de ação,e somente a toxina STa tem sido associada a doenças em humanos (BROOKS et al., 2009).

\subsubsection{E. coli Entoropatogênica (EPEC)}

A EPEC foi relacionada pela primeira vez com diarréia humana na Alemanha em 1930 e confirmada em 1945 na Inglaterra, estando envolvida em surtos de diarréia É responsável pela diarréia em lactentes, principalmente em países em desenvolvimento (BROOKS et al., 2009). Subdividem-se em duas categorias: EPEC típica e EPEC atípica. Ambas provocam lesão no epitélio intestinal. Após atravessarem a barreira gástrica, as EPEC aderem à mucosa dos intestinos delgado e grosso causando alterações que levam à diarréia (NATARO e KAPER, 1998).

O homem é o principal reservatório das EPEC típicas. Acredita-se que a transmissão ocorra por meio da ingestão de água e alimentos contaminados e contato pessoal (MARTINEZ e TRABULSI, 2008).

Dentre as alterações provocadas pelas EPEC na mucosa intestinal, a mais estudada é a lesão "attaching and effacing" (A/E). A bactéria fixa-se intimamente as células do epitélio intestinal e provoca o desaparecimento das microvilosidades intestinais (NATARO e KAPER, 1998). Essa lesão é codificada por genes que se encontram na ilha de patogenicidade (PAI) denominada de LEE (locus of enterocyte effacement) (KAPER et al., 2004).

Algumas cepas de EPEC produzem a toxina EAST1, codificada pelo gene ast $A$. Não se sabe a importância ou a função dessa toxina em EPEC. As cepas de 
EPEC que contem o gene astA são mais frequentemente isoladas de adultos (NATARO e KAPER, 1998).

As cepas de EPEC possuem o plasmídeo de 70 a $100 \mathrm{~kb}$ chamado de EAF (EPEC adherence factor). Esse plasmídeo codifica as fímbrias do tipo IV denominadas de bundle-forming pilus (BFP), as quais são responsáveis pela aderência entre bactérias e a aderência as células epiteliais (NATARO e KAPER, 2004).

Cepas de EPEC atipicas contem apenas o LEE (KAPER et al., 2004). A adesão íntima de EPEC às células epiteliais são mediadas por uma proteína de membrana externa chamada intimina, a qual é codificada pelo gene eae (NATARO e KAPER, 1998).

Testes fenotípicos e moleculares são realizados para diagnosticar esse patótipo de $E$. coli como a pesquisa de adesão a células HeLs ou HEp-2, fímbria BFP e identificação sorológica com anti-soro O e H. Entre os métodos moleculares, destaca-se a PCR e sondas genéticas para a detecção do plasmídeo EAF (NATARO e KAPER, 1998).

\subsubsection{E. coli Enterohemorrágica (EHEC)}

Caracteriza-se pela produção de toxinas (toxina de shiga ou Stx) semelhantes a Shiga toxina produzida Shigella dysenteria. EHEC causa várias doenças no homem, as quais variam de casos assintomáticos, diarréia branda até casos mais graves de colite hemorrágica $(\mathrm{CH})$ que pode evoluir para complicações extra- 
intestinais, sendo a de maior gravidade a síndrome hemolítica urêmica (SHU) (KAPER et al., 2004).

O trato intestinal de bovinos é o principal reservatório de EHEC e inicialmente os surtos foram associados ao consumo de hambúrgueres (NATARO e KAPER, 1998).

Cepas de EHEC do sorotipo O157H: 7 são os patógenos mais importantes na América do Norte, Japão e no Reino Unido, mas outros sorotipos diferentes, particularmente aqueles do sorogrupo $\mathrm{O} 26$ e 0111 também podem causar doenças e são mais proeminentes que o $\mathrm{O} 157 \mathrm{H}: 7$ em vários países (KAPER et al., 2004).

Stx é uma potente citotoxina que leva a morte e a outros sintomas em indivíduos infectados por EHEC. A família Stx é dividida em dois subgrupos: Stx1 e Stx2 e são codificadas em um bacteriófago inserido no cromossomo (NATARO e KAPER, 1998).

\subsubsection{E. coli Enteroagregativa (EAEC)}

EAEC é um grupo de bactérias que abrange sorogrupos de $E$. coli que aderem a linhagens às células HEp-2 ou HeLa. O patótipo secreta a toxina EAST-1, possui fimbrias denominadas de aggregativre adherence factors (AAF) I, II e III, as quais estão relacionadas ao padrão de aderência agregativa (AA) e são codificadas por plasmídeos (NATARO e KAPER, 1998).

EAEC provoca o aumento da secreção de muco na mucosa intestinal, e as bactérias formam um emaranhado em uma espessa camada de biofilme. 
Provavelmente, a formação do biofilme esteja relacionada à capacidade da bactéria colonizar e causar doença e má absorção de nutrientes (MARTINEZ e TRABUSLI, 2008).

O diagnóstico de EAEC é feito com base em ensaios de aderência as células HEp-2 ou HeLa para pesquisar o padrão AA (NATARO e KAPER, 1998).

\subsubsection{E.coli Enteroinvasiva (EIEC)}

EIEC se caracteriza por invadir o epitélio do cólon e sua patogenicidade é muito semelhante a da bactéria Shigella spp, sendo que ambas podem elaborar uma ou mais enterotoxinas que são capazes de causar diarréia. Em casos de infecção severa por EIEC observa-se uma reação inflamatória intensa com presença de ulcerações do epitélio intestinal (NATARO e KAPER, 1998; BROOKS et al., 2009).

As infecções causadas por EIEC acometem crianças maiores de dois anos de idade e adultos. O homem é o reservatório e a transmissão se dá pela ingestão de água e alimentos contaminados (MARTINEZ e TRABUSLI, 2008).

\subsubsection{E. coli Difusamente Aderente (DAEC)}

DAEC possuem padrão de aderência difusa às células do hospedeiro que é mediada por fímbrias, denominadas de F1845, sendo que o sorotipo mais comumente identificado com este padrão é o O126: H27 (NATARO e KAPER, 1998). 
Tem sido associada como a causa de diarréias em crianças, principalmente entre as maiores de doze anos de idade. Pacientes infectados por DAEC apresentam diarréia aquosa (NATARO e KAPER, 1998; KAPER et al., 2004).

\subsection{GRUPO FILOGENÉTICO}

Outra maneira de classificar as cepas de $E$. coli é através da determinação do grupo filogenético. Estudos epidemiológicos moleculares demonstraram que isolados de $E$. coli podem ser classificados em quatro grupos filogenéticos: A, B1, B2 e D (CLERMONT et al., 2000).

A determinação do grupo filogenético é feita pela reação de PCR multiplex empregando três marcadores: o gene chuA, que está relacionado ao transporte de ferro na EHEC 0157H:7; o gene yjaA de função desconhecida mas identificado em isolados de $E$. coli $\mathrm{K}-12$, e um fragmento de DNA TSPE4.C2 (CLERMONT et al., 2000). Os perfis para os grupos filogenéticos estão apresentados na figura 1. 


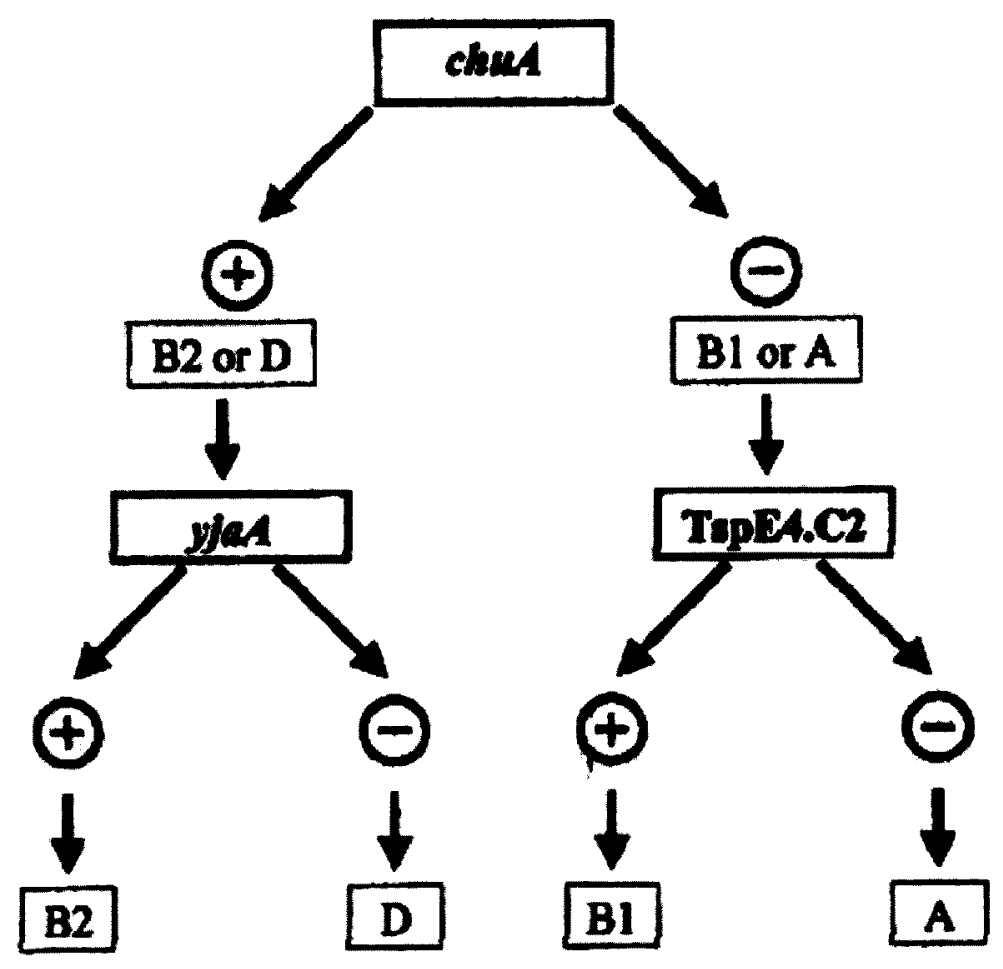

Figura 1- Representação dos grupos filogenéticos utilizando iniciadores para os genes chuA, yjaA e fragmento de DNA TSPE4.C2. Adaptado de (CLERMONT et al., 2000).

A maioria dos isolados patogênicos de $E$. coli extraintestinal pertencem ao grupo filogenético $\mathrm{B} 2$, em menor frequência ao grupo $\mathrm{D}$, e os isolados de $E$. coli comensal são usualmente do grupo A e B1 (PICARD et al., 1999; CLERMONT et al., 2000; GIRARDEAU et al., 2005).

Vários estudos têm sido realizados com a finalidade de diferenciar cepas de $E$. coli patogênicas de cepas comensais. 
DURIEZ et al. (2001) estudaram 168 cepas comensais de $E$. coli isoladas de fezes de três populações humanas distintas geograficamente. Os resultados revelaram que os grupos filogenéticos A e B1 são mais freqüentes nesse tipo de amostra.

AFSET et al. (2008) realizaram um estudo epidemiológico com crianças saudáveis e com diarreia e observaram que os grupos filogenéticos A, B1 e D não tiveram associação significativa com diarréia, e que as cepas pertencentes ao grupo B2 foram mais comuns em crianças saudáveis do que em crianças com diarréia.

No trabalho realizado por ORSI et al. (2007), os autores isolaram 49 cepas de E. coli de diferentes fontes de água de consumo. A maioria das cepas analisadas pertencia ao grupo filogenético $\mathrm{B} 1$.

Em 2008, ORSI et al. verificaram a distribuição do grupo filogenético em cepas de $E$. coli isoladas dos rios Sorocaba e Jaguari localizados no estado de São Paulo, e encontraram em ambos os rios cepas pertencentes ao grupo D. SABATÉ et al. (2008) relataram que o grupo A é o mais comum em cepas de $E$. coli provenientes de amostras de águas residuais.

Estudos filogenéticos de cepas de $E$. coli provenientes de amostras de queijo indicou que o grupo A ocorre com maior frequência nesse tipo de amostra (HAMMAD, et al.,2009; PEDRO, 2009).

Os estudos mostram a importância da pesquisa do grupo filogenético, pois cepas de $E$. coli potencialmente patogênicas podem estar circulando no ambiente e trocando o material genético entre elas, o que pode representar risco à Saúde. 


\subsection{ANTIMICROBIANOS}

Antimicrobianos são substâncias capazes de inibir parcialmente ou totalmente o crescimento e a multiplicação de microrganismos. São classificados como antibióticos (substâncias químicas produzidas por microrganismos) e como quimioterápicos (substâncias sintetizadas ou produtos microbianos modificados estruturalmente em laboratório) (MONTELLI e SADATSUNE, 2001).

Segundo TAVARES (2009b) os agentes antimicrobianos possuem os seguintes mecanismos de ação:

- Inibição da síntese de parede ( $\beta$-lactâmicos: penicilinas, cefalosporinas, carbapenens; glicopeptídeos: vancomicina e teicoplanina).

- Alteração da integridade da membrana celular (polimixinas: polimixina B e colistina).

- Inibição da síntese protéica (macrolídeos, lincosamidas, tetraciclinas e aminoglicosídeos).

- Inibição da síntese de ácidos nucléicos (quinolonas e rifampicina).

\subsection{RESISTÊNCIA BACTERIANA}

A resistência aos antimicrobianos, entre os vários gêneros bacterianos representa atualmente um importante problema para a saúde pública mundial (WANG et al.,2006). 
Microrganismos resistentes podem ser selecionados pelos antimicrobianos por meio do esgoto hospitalar, efluentes urbanos, pelo processo de digestão anaeróbica nas estações de tratamento de esgoto ou no solo. Além disso, bactérias resistentes são excretadas e lançadas no esgoto ou no solo e em outros compartimentos ambientais (KÜMMERER, 2003).

Em regiões áridas, águas de reuso contendo bactérias resistentes a antimicrobianos são usadas para irrigação e o lodo serve como fertilizante. Esta prátca permite a entrada de microrganismos resistentes diretamente na cadeia alimentar e a introdução dos genes de resistência em ecossistemas naturais microbianos. Nesses ecossistemas, as bactérias não patogênicas podem servir como reservatório desses genes (KÜMMERER, 2003; BAQUERO et al., 2008).

Além disso, a medicina veterinária e a agricultura contribuem com o aumento da resistência bacteriana. Os antibióticos são utilizados na profilaxia e promoção do crescimento animal (WITTE, 1998). Eritromicina e amoxicilina são exemplos de antimicrobianos utilizados no tratamento de patógenos humanos e também na promoção do crescimento e melhoria da eficiência alimentar no animal (ALLEN, 2010).

São vários os mecanismos de resistência bacteriana aos antimicrobianos, como: (i) produção de enzimas que degradam ou inativam o antimicrobiano, (ii) alteração da permeabilidade da membrana que impede ou dificulta a entrada do antimicrobiano na célula, (iii) efluxo ativo de antimicrobiano e (iv) alteração do sítio alvo do antimicrobiano (PBPs) (TENOVER, 2006). 
Quando os microrganismos são expostos a antimicrobianos inadequados e em dosagens inadequadas, ocorre a eliminação das cepas suscetíveis e a sobrevivência das resistentes, esse processo é denominado de pressão seletiva (DROPA, 2006).

Visando a sobrevivência e o crescimento, os microrganismos desenvolvem resistência aos antimicrobianos através de mutações, aquisição de genes entre outros (TAVARES, 2009c).

Os genes de resistência podem estar localizados no cromossomo ou em elementos móveis, como plasmídeos. A localização desses genes em elementos móveis facilita sua transferência entre os microrganismos, mesmo de espécies diferentes (MOREIRA et al., 2008). A disseminação de genes responsáveis pela resistência aos antibióticos pode ocorrer por transmissão vertical, ou seja, quando uma bactéria se divide e todo seu genoma é duplicado originando uma nova célula idêntica, ou por transmissão horizontal, na qual bactérias da mesma espécie ou de espécies e gêneros diferentes trocam genes de resistência por transferência de DNA por meio de processos como, conjugação, transdução, transformação e transposição (FROST et al., 2005; TENOVER, 2006).

$\mathrm{Na}$ transmissão horizontal, alguns elementos genéticos estão associados com a mobilização de genes de resistência, como sequências de inserção, integrons e transposons (TENOVER, 2006). 


\subsubsection{Antimicrobianos $\beta$-Lactâmicos}

Os antimicrobianos $\beta$-lactâmicos constituem uma importante classe de medicamentos usados no tratamento de infecções bacterianas (PFEIFER et al., 2010). Caracterizam-se por possuírem um grupamento químico heterocíclico azetidinona denominado de anel $\beta$-lactâmico. $O$ anel $\beta$-lactâmico é o responsável pela atividade antimicrobiana, quando o mesmo é rompido o antimicrobiano é inativado (DROPA, 2006; TAVARES, 2009b).

Os $\beta$-lactâmicos inibem a síntese da parede celular bacteriana, fixando-se às PBPs (penicilin-binding proteins) e impedindo a produção de peptideoglicano (TAVARES, 2009b), o qual é um componente fundamental da parede celular bacteriana (CASTANHEIRA, 2005).

Os principais grupos de $\beta$-lactâmicos incluem as penicilinas, cefalosporinas, monobactâmicos e carbapenêmicos (TAVARES, 2009b), sendo que os antimcrobianos $\beta$-lactâmicos representam aproximadamente $50 \%$ do consumo mundial de antibióticos e o uso indiscriminado tem exercido papel fundamental na seleção de microrganismos resistentes pré-existentes em uma determinada população (CHAH e OBOEGBULEM, 2007; TAVARES, 2009b).

O principal mecanismo de resistência a classe de antimicrobianos $\beta$ lactâmicos, em bactérias Gram negativas, é a produção de $\beta$-lactamases (BUSH e JACOBY, 2010). 


\section{6 $\beta$-LACTAMASES}

As $\beta$-lactmases são enzimas que catalisam a hidrólise do anel $\beta$ - lactâmico, inativando sua ação antimicrobiana (MENEZES et al., 2007).

Diversos tipos de $\beta$-lactamases já foram descritos e várias tentativas de classificá-las também. Entretanto, as duas classificações mais importantes são a de Ambler e a de Bush-Jacoby-Medeiros (CASTANHEIRA, 2005).

A classificação de Ambler foi feita com base na estrutura molecular das $\beta$ lactamases, de acordo com a seqüência de aminoácidos. Quatro classes moleculares principais de $\beta$-lactamases foram descritas: A) $\beta$-lactamases de espectro ampliado (ESBLs), penicilinases e carbenicilinases; B) metalo- $\beta$-lactamases; C) cefalosporinases cromossomais; D) oxacilinases (CASTANHEIRA, 2005). Em 2010, foi atualizada por BUSH e JACOBY.

A classificação molecular de Ambler e a de Bush-Jacoby-Medeiros estão descritas no quadro 1.

As $\beta$-lactamases são divididas em três principais grupos: beta-lactamases de espectro estendido (ESBL), metalo- $\beta$-lactamases (MBL) e cefalosporinases cromossômicas (AmpC). 
Quadro 1-Esquema de classificação para $\beta$-lactamases.

\begin{tabular}{|c|c|c|c|c|c|c|c|}
\hline \multirow{2}{*}{$\begin{array}{l}0 \\
= \\
0\end{array}$} & \multirow{2}{*}{ 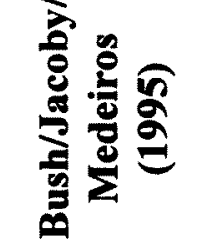 } & \multirow{2}{*}{ 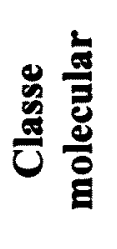 } & \multirow{2}{*}{ Substrato } & \multicolumn{2}{|c|}{ Inibido por } & \multirow{2}{*}{ Características } & \multirow{2}{*}{$\begin{array}{l}\text { Enzimas } \\
\text { Representativas }\end{array}$} \\
\hline & & & & $A C / T^{*}$ & EDTA $^{*}$ & & \\
\hline 1 & 1 & $\mathrm{C}$ & Cefalosporinas & Não & Não & Hidrolisam cefalosporinas e cefamicinas & $\begin{array}{l}\text { E. coli AmpC, P99, } \\
\text { ACT-1, CMY-2, FOX- } \\
\text { 1,MIR-1 }\end{array}$ \\
\hline le & Não inclusa & $\mathrm{C}$ & Cefalosporinas & Não & Não & $\begin{array}{l}\text { Hidrolisam mais ceftazidima que outras } \\
\text { oximino- } \beta \text {-lactâmicos }\end{array}$ & $\mathrm{GCl}, \mathrm{CMY}-37$ \\
\hline $2 \mathrm{a}$ & $2^{\mathbf{a}}$ & A & Penicilinas & Sim & Não & $\begin{array}{l}\text { Hidrolisam mais benzilpenicilinas que } \\
\text { cefalosporinas }\end{array}$ & $\mathrm{PCl}$ \\
\hline $2 b$ & $2 b$ & A & Penicilinas e cefalosporinas & Sim & Não & $\begin{array}{l}\text { Hidrolisam benzilpenicilinas e } \\
\text { cefalosporinas igualmente }\end{array}$ & $\begin{array}{c}\text { TEM-1, TEM-2, SHV- } \\
1\end{array}$ \\
\hline 2 be & $2 \mathrm{be}$ & A & $\begin{array}{l}\text { Cefalosporinas de espectro } \\
\text { estendido e monobactâmicos }\end{array}$ & Sim & Não & $\begin{array}{l}\text { Hidrolisam oximino- } \beta \text {-lactâmicos } \\
\text { (cefotaxima, ceftazidima, ceftriaxona, } \\
\text { cefepime, aztreonam) }\end{array}$ & $\begin{array}{l}\text { TEM-3, SHV-2, CTX- } \\
\text { M15, PER-1, VEB-1 }\end{array}$ \\
\hline $2 b r$ & $2 b r$ & A & Penicilinas & Não & Não & $\begin{array}{l}\text { Resistentes ao ácido clavulânico, } \\
\text { sulbactam e tazobactam }\end{array}$ & TEM-30, SHV-10 \\
\hline 2ber & Não inclusa & A & $\begin{array}{l}\text { Cefalosporinas de espectro } \\
\text { estendido e monobactâmicos }\end{array}$ & Não & Não & $\begin{array}{l}\text { Hidrolisam oximino- } \beta \text {-lactâmicos } \\
\text { combinados com resistência ao acido } \\
\text { clavulânico, sulbactam e tazobactam }\end{array}$ & TEM -50 \\
\hline $2 \mathrm{c}$ & $2 \mathrm{c}$ & A & Carbenicilinas & Sim & Não & Hidrolisam carbapenêmicos & PSE-1, CARB-3 \\
\hline $2 \mathrm{ce}$ & Não inclusa & A & Carbenicilinas e cefepimes & Sim & Não & Hidrolisam carbapenêmicos, cefpirome & RTG-4 \\
\hline
\end{tabular}

Legenda: *AC: ácido clavulânico; TZB: tazobactam;** EDTA: ácido etilenodiaminotetracético; DESC.: desconhecida; NR: Não realizado. FONTE: BUSH e JACOBY(2010). 
Quadro 1-Esquema de classificação para $\beta$-lactamases (continuação).

\begin{tabular}{|c|c|c|c|c|c|c|c|}
\hline \multirow{2}{*}{ 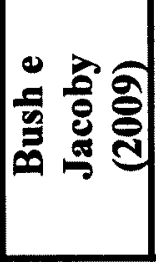 } & \multirow{2}{*}{ 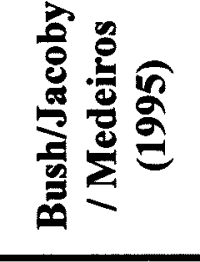 } & \multirow{2}{*}{ 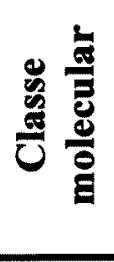 } & \multirow{2}{*}{ Substrato } & \multicolumn{2}{|c|}{ Inibido por } & \multirow{2}{*}{ Características } & \multirow{2}{*}{$\begin{array}{c}\text { Enzimas } \\
\text { Representativas }\end{array}$} \\
\hline & & & & AC/ TZB* & EDTA $^{* *}$ & & \\
\hline $2 d$ & $2 \mathrm{~d}$ & D & Cloxacilinas & Variável & Não & Hidrolisam as cloxacilinas ou oxacilinas & OXA-1, OXA-10 \\
\hline 2de & Não inclusa & D & $\begin{array}{l}\text { Espectro estendido de } \\
\text { cefalosporinas }\end{array}$ & Variável & Não & $\begin{array}{c}\text { Hidrolisam a cloxacilinas ou oxacilinas e } \\
\text { oximino- } \beta \text {-lactâmicos }\end{array}$ & OXA-11, OXA-15 \\
\hline $2 \mathrm{df}$ & Não inclusa & D & Carbapenêmicos & Variável & Não & $\begin{array}{l}\text { Hidrolisam cloxacilinas ou oxacilinas e } \\
\text { carbapenêmicos }\end{array}$ & OXA-23, OXA-48 \\
\hline $2 e$ & $2 e$ & A & $\begin{array}{l}\text { Cefalosporinas de espectro } \\
\text { estendido }\end{array}$ & Sim & Não & $\begin{array}{l}\text { Hidrolisam as cefalosporinas, inibidas por } \\
\text { ácido clavulânico, mas não aztreonam }\end{array}$ & CepA \\
\hline $2 \mathrm{f}$ & $2 f$ & A & Carbapenêmicos & Variável & Não & $\begin{array}{l}\text { Hidrolisam os carbapenêmicos, oximino- } \\
\beta \text {-lactâmicos e cefamicinas }\end{array}$ & KPC-2, IMI-1, SME-1 \\
\hline $3 a$ & 3 & $\begin{array}{l}\mathrm{B}(\mathrm{B} 1) \\
\mathrm{B}(\mathrm{B} 3)\end{array}$ & Carbapenêmicos & Não & Sim & $\begin{array}{l}\text { Hidrolisam os antibióticos de amplo } \\
\text { espectro incluindo os carbapenêmicos, } \\
\text { mas não monobactâmicos }\end{array}$ & $\begin{array}{l}\text { IMP-1, VIM-1, CcrA, } \\
\text { IND-1, L1, CAU-1, } \\
\text { GOB-1, FEZ-1 }\end{array}$ \\
\hline $3 b$ & 3 & B/B2 & Carbapenêmicos & Não & Sim & $\begin{array}{l}\text { Preferencialmente hidrolisam os } \\
\text { carbapenêmicos }\end{array}$ & CphA, Sfh-1 \\
\hline $\begin{array}{c}\text { Não } \\
\text { inclusa }\end{array}$ & 4 & DESC. & $\begin{array}{c}\text { Enzimas não sequenciadas e não } \\
\text { classificadas }\end{array}$ & NR & NR & NR & NR \\
\hline
\end{tabular}

Legenda: *AC: ácido clavulânico; TZB: tazobactam; ** EDTA: ácido etilenodiaminotetracético; FONTE: BUSH e JACOBY (2010). 


\subsection{1 $\beta$-lactamases de Espectro Estendido-ESBL}

A produção de $\beta$-lactamases de espectro estendido (ESBL) por Enterobacteriaceae é o mecanismo de resistência mais comum aos antimicrobianos $\beta$-lactâmicos (PFEIFER et al.,2010).

As ESBLs pertencem a classe A ou D de Ambler ou as classes 2 be ou $2 \mathrm{~d}$ de Bush-Jacoby-Medeiros, são enzimas capazes de hidrolisar penicilinas, cefalosporinas de primeira, segunda, terceira e quarta gerações e o monobactâmico, aztreonam, mas não hidrolisam as cefamicinas nem carbapenems. Apresentam um aminoácido serina em seu centro ativo, sendo este seu principal resíduo catalítico, e geralmente são inibidas por clavulanato, sulbactam e/ou tazobactam (BUSH et al., 1995; DROPA, 2006; BALSALOBRE, 2009).

As ESBLs resultam principalmente de mutações das enzimas TEM-1 e SHV1, e ocorrem com maior frequência em Enterobacteriaceae. Podem estar localizadas no cromossomo bacteriano ou mediadas por plasmídeos (CASTANHEIRA, 2005; MENEZES et al., 2007).

A TEM-1 foi a primeira $\beta$-lactamase descrita, tendo sido isolada em $E$. coli na Grécia em 1960. A resistência a ampicilina em $E$. coli deve-se, na maioria das vezes, a presença dessa enzima (LIVERMORE, 1995). Atualmente existem 195 enzimas da família TEM (http://www.lahey.org/Studies), sendo a maioria classificada como ESBL. 
Outra $\beta$-lactamase encontrada principalmente em Enterobacteriaceae a SHV, sendo mais frequentemente mediada por genes plasmidiais em $E$. coli e por genes cromossômicos em $K$. pneumoniae, entretanto há relatos na literatura dessas enzimas sendo encontradas em outras enterobactérias e em bactérias Gram negativas não fermentadoras da glicose, como Pseudomonas aeruginosa. Quando possuem espectro estendido, são resistentes à maioria dos $\beta$-lactâmicos, exceto carbapenêmicos e também são capazes de hidrolisar às cefalosporinas de primeira a quarta geração (LIVERMORE, 1995; BRADFORD, 2001).

Em 1989, na Alemanha, foi relatado um isolado clínico de $E$. coli que produzia uma nova ESBL, denominada de CTX-M-1, que caracterizava-se pela capacidade de hidrolisar cefotaxima (BAUERNFEID et al., 1989). Foram originadas provavelmente a partir da enzima AmpC de Kluyvera ascorbata, por apresentar alto grau de homologia entre si (BRADFORD, 2001; BONNET, 2004).

De acordo com a literatura existem outros grupos de ESBLs como OXA, TLA, BES, PER, GES, VEB, SFO, BEL (BRADFORD, 2001; DALMARCO et al., 2006).

1.6.2 Metalo- $\beta$-lactamases- MBL

Desde 1990 diversas MBLs codificadas por elementos móveis tem emergido em importantes patógenos Gram negativos (CORNAGLIA et al., 2011). 
As MBLs pertencem a classe $\mathrm{B}$ de Ambler ou à classe 3 de Bush-JacobyMedeiros e hidrolisam a maioria dos $\beta$-lactâmicos, incluindo os carbapenêmicos, mas não hidrolisam os monobactâmicoss, como aztreonam (PFEIFER et al., 2010). São inibidas pelo ácido etilenodiaminotetracético (EDTA) ou compostos derivados do tiol. Necessitam de dois íons divalentes, usualmente zinco, como cofatores para a reação de hidrólise do anel $\beta$-lactâmico (CASTANHEIRA, 2005; MENDES et al., 2006).

São produzidas constitutivamente em algumas espécies bacterianas, como Stenotrophomonas maltophilia, Bacillus cereus, Bacteróides fragilis, Aeromonas sp, Elizabethkingia meningoseptica (Chryseobacterium meningosepticum). Contudo, desde o início da década de 90 , novos genes codificadores de MBL têm sido descritos em patógenos clinicamente importantes, como Pseudomonas spp., Acinetobacter spp. e em membros da familia Enterobacteriaceae (CASTANHEIRA, 2005).

Os genes codificadores de MBLs podem ser encontrados em estruturas genéticas que conferem mobilidade aos genes, sendo então conhecidos como MBLs móveis ou adquiridas (CASTANHEIRA, 2005; MENDES et al., 2006).

IMP E VIM são tipos de MBLs adquiridas encontradas com maior freqüência em bactérias Gram negativas patogênicas. Foram descritas originalmente em $P$. aeruginosa e $A$. baumannii e atualmente estão amplamente distribuídas em Enterobacteriaceae (PFEIFER et al.,2010). 
Em 2002, TOLEMAN et al. descreveram uma nova enzima, SPM-1, a qual foi isolada em uma amostra de $P$. aeruginosa no Brasil. Desde então, não ocorreram relatos da presença dessa enzima em outras espécies bacterianas (MENDES, 2005).

Recentemente uma nova enzima MBL, NDM-1 foi relatada em $K$. pneumoniae, na Índia (YONG et al., 2009).

São conhecidas outras enzimas MBLs adquiridas: GIM-1(CASTANHEIRA et al., 2004), SIM-1(LEE et al., 2005), AIM (YONG et al., 2007), KHM (SEKIGUCHI et al., 2008), DIM (POIREL et al., 2010) e SMB (WACHINO et al., 2011).

\subsection{3 $\beta$-lactamases AmpC}

As cefalosporinases cromossômicas ou AmpC pertencem à classe $\mathrm{C}$ de Ambler ou à classe 1 de Bush - Jacoby - Medeiros e são codificadas por vários membros da família Enterobacteriaceae e por outros microrganismos (BUSH e JACOBY, 2010).

Bactérias que possuem genes ampC cromossômicos produzem $\beta$-lactamases AmpC em baixos níveis, o que confere diminuição de sensibilidade ou resistência a cefamicinas, como a cefoxitina. Essa característica intrínseca também confere diminuição de sensibilidade ou resistência às penicilinas e cefalosporinas de $1^{\mathrm{a}}$ e $2^{\mathrm{a}}$ geração (PEREZ-PEREZ e HANSON, 2002). As enzimas do tipo AmpC não são sensiveis aos inibidores de $\beta$-lactamases comercialmente disponíveis como o ácido clavulânico, sulbactam ou tazobactam (THOMSON, 2010), entretanto são inativadas por oxacilina e inibidas pelo ácido fenilborônico ( PITOUT, 2008). 
Em bactérias do grupo CESP (Citrobacter freundii, Enterobacter spp., Serratia spp., Providencia spp.) e também Proteus spp., Hafnia alvei, Morganela morganii e $P$. aeruginosa, as quais possuem o gene ampC cromossômico, a resistência às cefalosporinas de $3^{\mathrm{a}}$ geração pode ocorrer quando há hiperprodução de AmpC. A hiperprodução ocorre devido à indução, mediante a presença de alguns antimicrobianos $\beta$-lactâmicos, como cefoxitina e imipenem, e por inibidores de $\beta$ lactamases, como ácido clavulânico, os quais são fortes indutores de AmpC. Caso não ocorra a exposição da bactéria a esses agentes indutores, a produção de $\mathrm{AmpC}$ ocorre em níveis basais ( LIVERMORE,1995; BUSH e JACOBY, 2010).

A hiperprodução de AmpC pode ocorrer também devido a mutações em genes reguladores da produção da enzima (PEREZ-PEREZ e HANSON, 2002; PATERSON, 2006). Entretanto, E. coli e Shigella spp. diferem de outros membros da família das Entrobacteriaceae, que possuem o gene ampC cromossômico, devido a hiperprodução de AmpC não ser induzida e sim em decorrência de mutações ocorridas nos promotores dos genes que codificam as enzimas (PEREZ-PEREZ e HANSON, 2002 ).

Quando hiperproduzidas, a ação hidrolítica destas enzimas pode conferir resistência a todas as penicilinas, cefalosporinas de $1^{\mathrm{a}}, 2^{\mathrm{a}}$ e $3^{\mathrm{a}}$ geração, cefamicinas e ao aztreonam, no entanto, a sensibilidade às cefalosporinas de $4^{\mathrm{a}}$ geração e aos carbapenêmicos é geralmente preservada (PEREZ-PEREZ e HANSON, 2002).

Em 1989 foi descrita a primeira AmpC mediada por plasmídeo, denominada de CMY-1 (BAUERNFEIND et al., 1989). Desde então, tem sido descritas outras 
enzimas como ACT, DHA, FOX, MIR, MOX, ACC, LAT e CFE (JACOBY, 2009; BUSH e JACOBY, 2010; PFEIFER et al., 2010).

\subsection{RESISTÊNCIA EM E. coli}

$E$. coli é um importante agente causador de infecções hospitalares e na comunidade. Nas últimas décadas, $E$. coli tem se tornado cada vez mais resistente aos antimicrobianos utilizados incluindo ampicilina, tetraciclina, ácido nalidixico e sulfametoxazol-trimetoprim (FOWARD et al., 2001), e com a introdução dos antimicrobianos pertencentes à classe das fluoroquinolonas tem sido observado o surgimento e disseminação de resistência a essas drogas (CASTANHEIRA et al.,2007; ITO et al., 2008; MENEZES et al.,2009; LAMIKANRA et al.,2011).

\subsubsection{Resistência aos Antimicrobianos e Presença de Genes}

BOEHME et al.(2004) estudaram a resistência aos antimicrobianos em Enterobacteriaceae isoladas de diferentes tipos de vegetais. As cepas de E. coli isoladas de brotos apresentaram resistência aos antimicrobianos ampicilina, gentamicina, estreptomicina, tetraciclina, ácido nalidíxico, co-trimoxazol, canamicina, ciprofloxacina e clorafenicol.

No estudo realizado por PANETO et al. (2007) isolados de E. coli provenientes de amostras de queijo cru foram resistentes a cefalotina, ácido nalidíxico, doxiciclina, tetraciclina e ampicilina. 
BORGES et al. (2008) isolaram $E$. coli do empadão comercializado em uma feira de lazer de Goiânia e testaram a susceptibilidade a antimicrobianos. E. coli mostrou-se resistente à tetraciclina e à cefalotina.

E. coli provenientes de amostras de frutos do mar e peixes tem sido resistentes aos antimicrobianos tetraciclina, estreptomicina, cefalotina, ampicilina e ticarcilina (RYU et al., 2012).

VIEIRA et al., (2008) realizaram um estudo para avaliar a qualidade microbiológica da água utilizada para o cultivo de ostras. Foram isoladas cepas de $E$. coli, as quais apresentaram resistência aos antimicrobianos ampicilina, tetraciclina, ácido nalidíxico, imipenem ,ciprofloxacina, sulfazotrin e nitrofurantoína.

FIGUEIRA et al (2011) isolaram cepas de E. coli de amostras de água superficial e verificaram que as mesmas eram resistentes à tetraciclina, estreptomicina, amoxicilina, ticarcilina e cefalotina.

No estudo realizado por KOO e WOO (2011) os autores identificaram a presença do gene tet $(A)$ em mais de $50 \%$ dos isolados de $E$. coli provenientes de amostras de carnes, peixes e alimentos processados.

MACHADO et al. (2008) relataram a presença dos genes TEM-25, SHV-2 e CTX-M-1, em cepas de E. coli provenientes de amostras de carcaças de frango e o gene SHV-12 em E. coli proveniente de fezes de suínos saudáveis.

HAMELIN et al. (2007) identificaram a presença do gene tet(A) em cepas de E. coli, provenientes de amostras ambientais. 
Ultimamente tem sido identificados vários grupos de $\beta$-lactamases AmpC mediada por plasmídeos, sendo CMY a mais comum produzida por E. coli. Essas enzimas conferem resistência bacteriana a penicilinas, penicilinas com inibidores de $\beta$-lacatamases e cefalosporinas incluindo cefamicinas e aztreonam (DOI e PATERSON, 2007).

HAMMAD et al. (2009) detectaram a presença dos genes CMY-4 e CMY-41 em cepas de $E$. coli isoladas de amostras de queijo, ainda no mesmo ano, AHMED et al relataram a presença do gene CMY-2 em cepas de E. coli provenientes de amostras de carne de frango.

A presença do gene CMY-2 foi relatada por MATASEJE et al. (2009) em cepas de E. coli isoladas de amostras de água de consumo e recreação, as quais mostraram- se resistentes a cefoxitina.

Estudos realizados com isolados clínicos de $E$. coli demonstraram a presença dos genes bla $_{\mathrm{CMY}-1-1 \mathrm{ike}}$, bla $_{\mathrm{CMY}-2}$, bla $_{\mathrm{CMY}-7}$, bla $_{\mathrm{CMY}-21}$ e bla $_{\mathrm{CMY}-42}$ (DESHPANDE et al., 2006; HOPKINS et al., 2006; NASEER et al., 2009; SIDJABAT et al., 2009; SINGTOHIN et al., 2010; HENTSCHKE et al., 2011).

No trabalho realizado por BOU et al. (2000) isolados clínicos de E. coli apresentaram resistência a cefoxitina, cefotetan, cefotaxime e ceftazidima. No mesmo trabalho também foi identificada à presença do gene FOX-4. DESHPANDE et al. (2006) identificaram os genes FOX-5 e DHA-1 em isolados clínicos de E. coli. HUSSAIN et al. (2011) relataram a presença dos genes bla $a_{\mathrm{SHV}}, b_{\mathrm{TEM}}, a_{\mathrm{T}} a_{\mathrm{CTX}-\mathrm{M}}$, bla $_{\mathrm{CrT}}$ e $b l a_{\mathrm{MOX}}$ em isolados clínicos de E. coli. 
No Brasil, alguns autores relataram a presença de genes de resistência em cepas de $E$. coli. DROPA et al. (2011) relataram a presença dos genes bla $a_{\mathrm{SHV}}, b_{\mathrm{TEM}}$ e bla $a_{\mathrm{CTX}-\mathrm{M}}$ em isolados clínicos de $E$. coli.

No trabalho realizado por CASTANHEIRA et al. (2007) foi relatado, pela primeira vez no Brasil, a presença do gene qnrAl entre os isolados clínicos de $E$. coli, os quais foram resistentes a ciprofloxacina.

PAVEZ et al. (2008) em estudo realizado com isolados clínicos de $E$. coli detectaram a presença dos genes $b l a_{\mathrm{TEM}}$ e $b l a_{\mathrm{CMY}-2}$ em todos os isolados.

No trabalho realizado por OLIVEIRA et al. (2009), os autores pesquisaram a presença dos genes $b l a_{\mathrm{SHV}}, b l a_{\mathrm{TEM}}$ e bla $a_{\mathrm{CTX}-\mathrm{M}}$ em isolados clínicos de $E$. coli e obtiveram como resultado somente a presença do gene bla CTX-M. $_{\text {. }}$

No trabalho realizado por CERGOLE-NOVELLA et al. (2010) os autores relataram pela primeira vez no Brasil a presença do genes CTX-M 14 e CTX-M 15 em isolados clínicos de $E$. coli.

D'ALINCOURT CARVALHO-ASSEF et al.(2010) relatam o primeiro caso de KPC no Brasil em isolados clínicos de $E$. coli.

ABREU et al. (2011) identificaram a presença dos genes $b l_{C T X-M}$ e $b l a_{T E M}$ em isolados clínicos de $E$. coli. No mesmo ano, CHAGAS et al. detectaram os genes $b l a_{\mathrm{SHV}}, b l a_{\mathrm{TEM}}$ e bla $a_{\mathrm{CTX}-\mathrm{M}}$ em $E$. coli isoladas de uma estação de tratamento de esgoto hospitalar. 


\section{OBJETIVOS}

\subsection{OBJETIVO GERAL}

Determinar o grupo filogenético e identificar a ocorrência dos genes de resistência a antimicrobianos em isolados de $E$. coli provenientes de amostras de alimentos, ambientais e clínicas, previamente isoladas e pertencentes à coleção de cultura do laboratório de Prática de Saúde Pública da Faculdade de Saúde Pública da Universidade de São Paulo.

\subsection{OBJETIVOS ESPECÍFICOS}

- Verificar a freqüência com que ocorrem os grupos filogenéticos A, B1, B2 e D.

- Identificar o perfil de suscetibilidade a diferentes classes de antimicrobianos.

- Pesquisar genes de resistência a antimicrobianos $\beta$-lactâmicos nos isolados.

- Discutir a importância para a saúde pública dos resultados obtidos quanto ao grupo filogenético e à presença dos genes de resistência. 


\section{MATERIAL E MÉTODOS}

\subsection{REISOLAMENTO E IDENTIFICAÇÃO DAS COLÔNIAS}

Foram utilizados para o estudo, 65 isolados de Escherichia coli pertencentes à coleção de cultura do laboratório de Prática de Saúde Pública, os quais já haviam sido previamente identificados por testes bioquímicos entre os anos de 1990 a 2006 , sendo a maioria proveniente de trabalhos já realizados.

Os isolados são oriundos de amostras de alimentos $(n=5)$, ambiental $(n=57)$ e clínicas $(\mathrm{n}=3)$, como descrtio na tabela 1 .

Tabela 1- Descrição dos isolados utilizados no presente estudo.

\begin{tabular}{llc}
\hline Procedência & Descrição & $\begin{array}{c}\mathbf{N}^{\circ} \text { total de } \\
\text { isolados }\end{array}$ \\
\hline Alimento & Queijo minas frescal & 5 \\
\hline \multirow{4}{*}{ Ambiente } & Fezes de bovinos sadios & 8 \\
\cline { 2 - 3 } & Água tratada & 6 \\
\cline { 2 - 3 } & Garrafões de água mineral* & 10 \\
\cline { 2 - 3 } & Água de ambiente pristino** & 33 \\
\hline Clínica & Pacientes com infecção hospitalar*** & $\mathbf{6 5}$ \\
\hline Total & &
\end{tabular}

*Garrafões de água mineral de marcas diferentes.

**Amostras de água doce coletadas de um ambiente que não havia sofrido nenhum tipo de ação antrópica, na época. As cepas são provenientes do Instituto de Ciências Biomédicas da USP, foram gentilmente fornecidas pela profa. Maria Teresinha Martins em 1990.

***Corrente sanguínea.

Os isolados encontravam-se armazenados a $-70^{\circ} \mathrm{C}$ em glicerol. Uma alíquota foi retirada do meio de armazenamento e semeada em caldo Lúria $0,5 \% \mathrm{NaCl}$ para ativação e crescimento dos isolados e incubados a $35^{\circ} \mathrm{C}$ por 18 a 24 horas. Após 
esse período, uma alíquota do caldo cultivado foi semeada em placas de ágar MacConkey e incubadas a $35^{\circ} \mathrm{C}$ por 18 a 24 horas.

Após o período de incubação, as colônias características de $E$. coli que apresentaram coloração vermelha, pela utilização da lactose, convexas e secas, foram selecionadas para a realização do teste de oxidase (KONEMAN et al., 2005). Posteriormente os isolados foram novamente armazenados em glicerol a $-70^{\circ} \mathrm{C}$.

\subsection{EXTRAÇÃO DO DNA TOTAL}

A extração do DNA total foi realizada por meio de choque térmico segundo CHAPMAN et al. (2001).

Os isolados foram semeados em $2 \mathrm{~mL}$ de caldo Lúria $0,5 \% \mathrm{NaCl}$ e incubados a $35^{\circ} \mathrm{C}$ por 18 a 24 horas.

$\mathrm{O}$ conteúdo foi centrifugado a $12.000 \mathrm{rpm}$ por 10 minutos a $24^{\circ} \mathrm{C}$. $\mathrm{O}$ sobrenadante foi descartado e o sedimento ressuspenso em $1 \mathrm{~mL}$ de água $\mathrm{MilliQ}^{\circledR}$ estéril. $O$ material homogeneizado foi transferido para um microtubo tipo eppendorf® de $1,5 \mathrm{~mL}$, o qual foi submetido à nova centrifugação a $12.000 \mathrm{rpm}$ por 5 minutos a $24^{\circ} \mathrm{C}$. O sobrenadante foi descartado e o sedimento ressuspenso em 200 $\mu \mathrm{L}$ de água MilliQ ${ }^{\circledast}$ estéril. A suspensão foi mantida em banho-maria a $95^{\circ} \mathrm{C}$ por 10 minutos, e em seguida colocada em freezer $-20^{\circ} \mathrm{C}$, por 30 minutos, para o rompimento das células bacterianas e liberação do DNA. Os microtubos foram retirados do freezer e mantidos em temperatura ambiente até o descongelamento. Em seguida foram novamente centrifugados a $12.000 \mathrm{rpm}$ por 10 minutos a $24^{\circ} \mathrm{C}$. Um 
volume de $200 \mu \mathrm{L}$ foi retirado do sobrenadante e transferido para um novo microtubo de $1,5 \mathrm{~mL}$ e posteriormente armazenado em freezer a $-20^{\circ} \mathrm{C}$.

\subsection{IDENTIFICAÇÃO DO GRUPO FILOGENÉTICO}

A identificação do grupo filogenético foi feita por PCR segundo CLERMONT et al. (2000). Os iniciadores utilizados e suas características estão descritos no quadro 2.

A partir do DNA obtido da extração por choque térmico, a reação foi realizada em um termociclador (Mastercycler gradient Eppendorf ${ }^{3}$ ), e para cada microtubo um volume final de $25 \mu \mathrm{L}$, contendo os seguintes reagentes: $5 \mu \mathrm{L}$ de DNA; tampão 5x; 1,5 mM cloreto de Magnésio; 200 uM de DNTPs; 0,3 uM de cada iniciador; 1,25 U de taq-DNA-polimerase e água MilliQ® suficiente para completar o volume de $25 \mu \mathrm{L}$.

A reação da PCR foi realizada com um ciclo inicial a $94^{\circ} \mathrm{C}$ por 2 minutos, 40 ciclos a $94^{\circ} \mathrm{C}$ por 4 minutos, $52^{\circ} \mathrm{C}$ por 1 minuto, $72^{\circ} \mathrm{C}$ por 1 minuto além de um ciclo de extensão final de reação a $72^{\circ} \mathrm{C}$ por 5 minutos. Os controles positivos utilizados foram: a cepa 1893 para o grupo A; cepa 399 para o grupo B1; cepas 339 e 1895 para o grupo B2 e a cepa 1848 para o grupo D; as quais foram adquiridas do Instituto Adolfo Lutz. 
Quadro 2- Relação dos iniciadores utilizados para determinação do grupo filogenético.

\begin{tabular}{|l|l|c|l|}
\hline Gene & Sequência (5'-3') & Produto (pb) & Referência \\
\hline $\begin{array}{l}\text { chuA F } \\
\text { chuA } \mathrm{R}\end{array}$ & $\begin{array}{l}\text { GACGAACCAACGGTCAGGAT } \\
\text { TGCCGCCAGTACCAAAGACA }\end{array}$ & 279 & \\
\hline $\begin{array}{l}\text { yjaA } \mathrm{F} \\
\text { yjaA } \mathrm{R}\end{array}$ & $\begin{array}{l}\text { TGAAGTGTCAGGAGACGCTG } \\
\text { ATGGAGAATGCGTTCCTCAAC }\end{array}$ & 211 & $\begin{array}{l}\text { Clermont et al. } \\
(2000)\end{array}$ \\
\hline $\begin{array}{l}\text { TSPE4C F } \\
\text { TSPE4C R }\end{array}$ & $\begin{array}{l}\text { GAGTAATGTCGGGGCATTCA } \\
\text { CGCGCCAACAAAGTATTACG }\end{array}$ & 152 & \\
\hline
\end{tabular}

\subsection{TESTE DE SENSIBILIDADE AOS ANTIMICROBIANOS}

O teste de sensibilidade aos antimicrobianos foi realizado pelo método de Disco-Difusão em ágar (Kirby-Bauer) seguindo as recomendações do Clinical and Laboratory Standards Institute (CLSI) de 2009. Foram utilizados 14 antimicrobianos descritos a seguir: ampicilina $(10 \mu \mathrm{g})$, cefalotina $(30 \mu \mathrm{g})$, cefotetan $(30 \mu \mathrm{g})$, cefoxitina $(30 \mu \mathrm{g})$, cefotaxima $(30 \mu \mathrm{g})$, ceftadizima $(30 \mu \mathrm{g})$, cefepima $(30 \mu \mathrm{g})$, aztreonam $(30 \mu \mathrm{g})$, imipenem $(10 \mu \mathrm{g})$, ertapenem $(10 \mu \mathrm{g})$, tetraciclina $(30 \mu \mathrm{g})$, gentamicina $(10 \mu \mathrm{g})$, ciprofloxacina $(05 \mu \mathrm{g})$ e sulfametoxazol/trimetoprim $(1,25 / 23,75 \mu \mathrm{g})$ (Quadro 3).

O inóculo foi preparado a partir de uma colônia isolada de ágar MacConkey e inoculada em solução salina $(2 \mathrm{~mL})$ seguindo o padrão de turvação de 0,5 da escala de McFarland. Após a preparação do inóculo, este foi transferido para a placa de ágar Müeller-Hinton com o auxílio de um swab estéril embebido da solução, em seguida foram colocados os discos de antimicrobianos. As placas foram incubadas a $35^{\circ} \mathrm{C}$ por 16 a 18 horas. 
A interpretação do teste foi realizada de acordo com o CLSI de 2012. Os isolados foram considerados sensíveis, intermediários ou resistentes considerando os valores para cada antimicrobiano apresentado no quadro abaixo (quadro 3).

Para controle de qualidade dos testes de sensibilidade aos antimicrobianos foi utilizada a cepa Escherichia coli ATCC25922.

Quadro 3- Lista de antimicrobianos e respectivos valores dos halos em mm.

\begin{tabular}{|c|c|c|c|c|}
\hline \multirow[b]{2}{*}{ Classe } & \multirow{2}{*}{$\begin{array}{c}\text { Agentes } \\
\text { antimicrobianos }\end{array}$} & \multicolumn{3}{|c|}{ Diâmetro da zona de inibição } \\
\hline & & $\mathbf{S}$ & $\mathbf{I}$ & $\mathbf{R}$ \\
\hline Penicilinas & Ampicilina & $\geq 17$ & $14-16$ & $\leq 13$ \\
\hline \multirow{4}{*}{$\begin{array}{l}\text { Cefalosporinas } \\
\text { (I, II, III, IV) }\end{array}$} & Cefalotina & $\geq 18$ & $15-17$ & $\leq 14$ \\
\hline & Cefepima & $\geq 18$ & $15-17$ & $\leq 14$ \\
\hline & Cefotaxima & $\geq 26$ & $23-25$ & $\leq 22$ \\
\hline & Ceftazidima & $\geq 21$ & $18-20$ & $\leq 17$ \\
\hline & Cefotetan & $\geq 16$ & $13-15$ & $\leq 12$ \\
\hline Cefamicinas & Cefoxitina & $\geq 18$ & $15-17$ & $\leq 14$ \\
\hline Monobactâmicos & Aztreonam & $\geq 21$ & $18-20$ & $\leq 17$ \\
\hline \multirow[b]{2}{*}{ Carbapenêmicos } & Ertapenem & $\geq 22$ & $19-21$ & $\leq 18$ \\
\hline & Imipenem & $\geq 23$ & $20-22$ & $\leq 19$ \\
\hline Aminoglicosídeos & Gentamicina & $\geq 15$ & $13-14$ & $\leq 12$ \\
\hline Tetraciclinas & Tetraciclina & $\geq 15$ & $12-14$ & $\leq 11$ \\
\hline Fluoroquinolonas & Ciprofloxacina & $\geq 21$ & $16-20$ & $\leq 15$ \\
\hline $\begin{array}{l}\text { Inibidores da via de } \\
\text { folato }\end{array}$ & $\begin{array}{l}\text { Sulfametoxazol- } \\
\text { trimetoprim }\end{array}$ & $\geq 16$ & $11-15$ & $\leq 10$ \\
\hline
\end{tabular}

Fonte: CLSI: 2012. 


\subsubsection{Identificação Fenotípica para Produção de ESBL}

Os isolados foram triados para produção de ESBL pelo teste sinérgico do duplo disco (BRADFORD, 2001). O teste foi realizado com os isolados que apresentaram halo reduzido para ceftazidima, cefotaxima e/ou aztreonam. Foram utilizados os discos de ceftazidima (CAZ) $(30 \mu \mathrm{g})$, cefotaxima (CTX) $(30 \mu \mathrm{g})$, cefepime (CPM) $(30 \mu \mathrm{g})$ e aztreonam (ATM) $(30 \mu \mathrm{g})$, e no centro um disco de amoxicilina + ácido clavulânico (AMC) $(20 / 10 \mathrm{mg})$. Nos isolados produtores de AmpC foram adicionados $400 \mu \mathrm{L}$ da diluição de cloxacilina $(0,1 \mathrm{~g} / 10 \mathrm{~mL})$ no meio ágar Müeller-Hinton para inibir a produção de enzima (WELDHAGEN et al., 2003).

O aumento na zona de inibição de um dos antimicrobianos em direção ao disco de amoxicilina + ácido clavulânico foi considerado um indicativo para a produção de ESBL (BRADFORD, 2001).

\subsubsection{Identificação Fenotípica para Produção de AmpC}

Para detecção de produção de AmpC foi empregada a metodologia de combinação de discos, nos isolados que apresentaram halo reduzido para cefoxitina e/ou cefotetan. Utilizaram-se os discos de cefoxitina (CFO) $(30 \mu \mathrm{g})$ e cefotetan (CTT) $(30 \mu \mathrm{g})$, os quais foram dispostos em placa de Petri contendo ágar MüellerHinton e o inóculo do micorganismo estudado a uma distância de 20 a $30 \mathrm{~mm}$ dos mesmos discos contendo $20 \mu \mathrm{L}$ de ácido fenilborônico (BA) $(20 \mathrm{mg} / \mathrm{ml})$. Um aumento maior ou igual a $5 \mathrm{~mm}$ na zona de inibição de um dos antibióticos associado ao inibidor (BA) indica a produção de AmpC (COUDRON et al., 2000). 


\subsubsection{Identificação Fenotípica para Produção de MBL}

Para a deteç̧ão de isolados produtores de MBL foi utilizada a técnica de combinação de discos, nos isolados que apresentaram halo reduzido para imipenem e/ou ertapenem. Em placa de Petri contendo ágar Müeller-Hinton foram dispostos de 20 a $30 \mathrm{~mm}$ os discos de imipenem (IMP) $(10 \mu \mathrm{g})$, meropenem (MER) (10 $\mu \mathrm{g})$ e ertapenem (ERT) $(10 \mu \mathrm{g})$ associados ao inibidor EDTA $0,5 \mathrm{M}(930 \mu \mathrm{g}$ ou $5 \mu \mathrm{L})$ (PITOUT et al., 2005). Um aumento maior ou igual a $7 \mathrm{~mm}$ na zona de inibição dos discos associados ao inibidor EDTA 0,5M indica a produção de MBL (PITOUT et al., 2005).

\subsection{IDENTIFICAÇÃO DOS GENES DE RESISTÊNCIA}

\subsubsection{Detecção dos Genes Codificadores de AmpC}

Para a pesquisa dos genes codificadores de AmpC foram utilizados os iniciadores previamente descrito por MOURA, (2010) conforme quadro 4. Cada microtubo de reação continha um volume total de $25 \mu \mathrm{L}$, com os seguintes reagentes nas respectivas concentrações: $5 \mu \mathrm{L}$ de DNA, tampão 10X, 200 uM de DNTPs, 0,2 uM de cada iniciador e 1,25U Taq-DNA-polimerase. Para a amplificação dos genes de resistência, a reação ocorreu em um termociclador (Mastercycler gradient Eppendorf ${ }^{8}$ ), com denaturação inicial a $94^{\circ} \mathrm{C}$ por 2 minutos, seguida de 30 ciclos compostos de denaturação a $94^{\circ} \mathrm{C}$ por 45 segundos, anelamento a $55^{\circ} \mathrm{C}$ por 1 minuto, e extensão a $72^{\circ} \mathrm{C}$ por 1 minuto e extensão final a $72^{\circ} \mathrm{C}$ por 10 minutos. Para a pesquisa dos genes de resistência $b l_{\mathrm{Mox}}$ e bla $a_{\mathrm{CMY}}$, foi utilizado como controle a cepa 
FSP 135/08; para o gene bla $a_{\mathrm{CMY}}$ (outros) o controle FSP 11/10; para os genes bla $a_{\mathrm{MR}}$, $b l a_{\mathrm{EBC}}$ e $b l a_{\mathrm{ACT}}$ foi utilizado o controle FSP 15/10; para o gene bla $a_{\mathrm{DHA}}$, o controle FSP 08/10; para o gene $b l a_{\mathrm{ACC},}$ o controle FSP 10/10; e para o gene $b l a_{\mathrm{FOX}}$, o controle FSP 09/10. Todos os controles citados acima foram fornecidos pelo Prof. Dr. Nilton Lincopan, do Instituto de Ciências Biomédicas da Universidade de São Paulo (ICB/USP).

Quadro 4- Iniciadores utilizados para pesquisa dos genes AmpC.

\begin{tabular}{|c|c|c|c|}
\hline Iniciador & Sequência $\left(5^{\prime}-3^{\prime}\right)$ & Produto & Gene alvo \\
\hline MOX/CMY F & TGCAACAACGACAATCCATCCT & \multirow{2}{*}{$947 \mathrm{pb}$} & \multirow{2}{*}{ 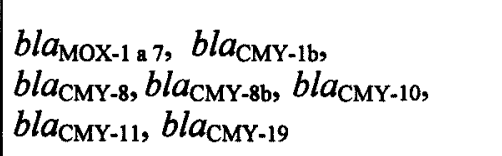 } \\
\hline MOX/CMY R & CATGACGAYGCCGATCC & & \\
\hline CMY F & ATGATGAAAAAATCGTTATGC & \multirow{2}{*}{$1149 \mathrm{pb}$} & \multirow{2}{*}{ 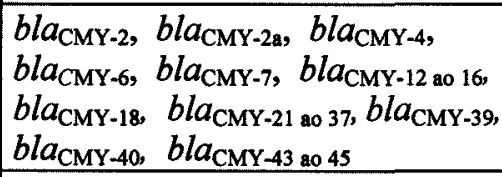 } \\
\hline CMY R & GCTTTTCAAGAATGCGCCA & & \\
\hline MIR F & TAAGCTGTGCCCTGCTGC & \multirow{2}{*}{$1106 \mathrm{pb}$} & \multirow{2}{*}{$\begin{array}{l}\text { bla }_{\mathrm{MIR}-1}, b l a_{\mathrm{MIR}-2} \\
\text { bla }_{\mathrm{MIR-3}}, \text { bla }_{\mathrm{MIR-8}}\end{array}$} \\
\hline MIR/EBC/ACT R & CCGCCTCAACGCGTGC & & \\
\hline EBC/ACT F & TTTGCTGCGCCCTGCTGC & \multirow{2}{*}{$1106 \mathrm{pb}$} & \multirow{2}{*}{$\begin{array}{l}b l a_{\mathrm{EBC}}, b l a_{\mathrm{ACT}-1}, b l a_{\mathrm{ACT}-2} \\
b l a_{\mathrm{ACT}-3}, b l a_{\mathrm{ACT}-5}\end{array}$} \\
\hline MIR/EBC/ACT R & CCGCCTCAACGCGGTGC & & \\
\hline DHA F & ATGGCGGTTGCCGTCTCC & \multirow{2}{*}{$779 \mathrm{pb}$} & \multirow{2}{*}{$b l a_{\mathrm{DHA}-1}, b l a_{\mathrm{DHA}-2}$} \\
\hline DHA R & CCAGGAAGCACGGTTATAC & & \\
\hline $\mathrm{ACC} F$ & ATGCGTAAAAAAATGCAGA & \multirow{2}{*}{$1270 \mathrm{pb}$} & \multirow{2}{*}{$b l a_{\mathrm{ACC}-1}, b l a_{\mathrm{ACC}-3}, b l a_{\mathrm{ACC}-4}$} \\
\hline ACC R & ATGCCATGCTGGCACAGG & & \\
\hline FOX F & ATGCAACAACGRCGTGCG & \multirow{2}{*}{$1139 \mathrm{pb}$} & \multirow{2}{*}{$b l a_{\mathrm{FOX}-1 \text { a } 7}$} \\
\hline FOX R & TCACTCGGCCAACTGACTC & & \\
\hline
\end{tabular}

Fonte: Moura, 2010 


\subsubsection{Deteç̧ão dos Genes Codificadores de MBL}

Para a pesquisa dos genes codificadores de MBL foram utilizados os iniciadores descritos no quadro 5. Cada microtubo de reação teve um volume total de $25 \mu \mathrm{L}$, com os seguintes reagentes nas respectivas concentrações: $5 \mu \mathrm{L}$ de DNA, tampão 10X, 200 uM de DNTPs, 0,2 uM de cada iniciador e 1,25U Taq-DNApolimerase. Para a amplificação dos genes de resistência, a reação ocorreu em um termociclador (Mastercycler gradient Eppendorf ${ }^{\text {) }}$, com denaturação inicial a $95^{\circ} \mathrm{C}$ por 5 minutos, seguida de 30 ciclos compostos de denaturação a $95^{\circ} \mathrm{C}$ por 1 minuto, anelamento a $55^{\circ} \mathrm{C}$ por 1 minuto, e extensão a $72^{\circ} \mathrm{C}$ por 1 minuto e extensão final a $72^{\circ} \mathrm{C}$ por 5 minutos. Para a amplificação do gene $b l a_{\mathrm{IMP}}$ a temperatura de anelamento foi de $40^{\circ} \mathrm{C}$.

Quadro 5- Iniciadores utilizados para pesquisa dos genes MBL.

\begin{tabular}{|c|c|c|c|c|}
\hline Iniciador & Sequência (5'-3') & Produto & $\begin{array}{l}\text { Gene } \\
\text { Alvo }\end{array}$ & Referências \\
\hline IMP F & GGAATAGRRTGGCTTAAYT & \multirow{2}{*}{$232 \mathrm{pb}$} & \multirow{2}{*}{$b_{l a} a_{I M P}$} & \multirow{4}{*}{$\begin{array}{l}\text { Balsalobre et al. } \\
(2009)\end{array}$} \\
\hline IMP R & GGTTTAAYAAARCAMCCACC & & & \\
\hline VIM F & GTTTGGTCGCATATCGCAAC & \multirow{2}{*}{$590 \mathrm{pb}$} & \multirow{2}{*}{$b_{l a}$} & \\
\hline VIM R & GAGCAAKTCYAGACCGCCC & & & \\
\hline SPM-1 F & CCTACAATCTAACGGCGACC & \multirow{2}{*}{$648 \mathrm{pb}$} & \multirow{2}{*}{ bla $_{S P M-1}$} & \multirow{2}{*}{$\begin{array}{l}\text { Zavascki et al. } \\
(2005)\end{array}$} \\
\hline SPM-1 R & TCGCCGTGTCCAGGTATAAC & & & \\
\hline
\end{tabular}

Os controles positivos utilizados para a pesquisa dos genes de resistência pertencem à coleção de cultura do Laboratório de Prática de Saúde Pública/FSP- 
USP: cepa FCF/USP Kp-IMP para o gene $b l a_{\mathrm{IMP}}$; cepa FCF/USP Ecl 75-10433 VIM1 para o gene bla $a_{\mathrm{VIM}}$; cepa FCF/USP PA 4811997 SPM-1 para o gene bla $a_{\mathrm{SPM}-1 .}$

\subsection{ELETROFORESE EM GEL DE AGAROSE}

Para visualização dos produtos da PCR, o gel de agarose (Amersham Biosciences) foi preparado com tampão tris-acetato-EDTA (TAE-1X) e corado com brometo de etídio $(1 \mu \mathrm{g} / \mathrm{mL})$, foi submetido à eletroforese com a intensidade de corrente elétrica de $6 \mathrm{~V} / \mathrm{cm}$. Em cada poço do gel foram adicionados $5 \mu \mathrm{l}$ das amostras previamente coradas com tampão carregador de amostra (glicerina e azul de bromofenol), e foram utilizados $2 \mu \mathrm{L}$ de marcador de pesos molecular de $100 \mathrm{pb}$ (MassRuler ${ }^{\mathrm{TM}}$ DNA Ladder, Fermentas). O gel foi visualizado em fonte de luz ultravioleta de $302 \mathrm{~nm}$, utilizando um transiluminador e as imagens foram capturadas pelo sistema Epi Chemi II Darkroom e software Labworks (UVP). 


\section{RESULTADOS}

Foram utilizados no presente estudo 65 isolados de $E$. coli para pesquisa do grupo filogenético, perfil de suscetibilidade aos antimicrobianos e genes de resistência.

\subsection{GRUPO FILOGENÉTICO}

Dos 65 isolados de $E$.coli que foram submetidos à pesquisa do grupo filogenético, $32,30 \%(21 / 65)$ corresponderam ao grupo A, $61,53 \%(40 / 65)$ ao grupo B1, 1,53\% (1/65) ao grupo B2 e 4,61 \% (3/65) ao grupo D. O filogrupo B1 foi o mais frequente entre os diferentes tipos de amostras (tabela 2).

Tabela 2- Distribuição do grupo filogenético em isolados de E.coli provenientes de diferentes tipos de amostras.

\begin{tabular}{lccccc}
\hline Amostra / Filogrupo & A & B1 & B2 & D & $\begin{array}{c}\text { No total de } \\
\text { isolados }\end{array}$ \\
\hline Queijo minas & 5 & - & - & - & 5 \\
Fezes de bovinos & 6 & 2 & & - & 8 \\
Água tratada & - & 3 & 1 & 2 & 6 \\
Água mineral & 10 & - & - & - & 10 \\
Ambiente Prístino & - & 33 & - & - & 33 \\
Isolado clínico & - & 2 & - & 1 & 3 \\
\hline Total & $\mathbf{2 1}$ & $\mathbf{4 0}$ & $\mathbf{1}$ & $\mathbf{3}$ & $\mathbf{6 5}$ \\
\hline
\end{tabular}




\subsection{ANÁLISE FENOTÍPICA DE SENSIBILIDADE AOS ANTIMICROBIANOS, PRODUÇÃO DE ENZIMAS $\beta$-LACTAMASES E DETECÇÃO DE GENES DE RESISTÊNCIA}

Do total de isolados (65) analisados, $16(24,61 \%)$ foram resistentes a ampicilina (AMP), 14 (21,53\%) a cefalotina (CFL), 4 (6,15\%) a cefotaxima (CTX), 6 $(9,23 \%)$ a cefotetan (CTT), $8(12,30 \%)$ a cefoxitina (FOX), $4(6,15 \%)$ a ceftazidima (CAZ), 2 ( 3,07\%) a aztreonam (ATM), 1 (1,53\%) a ertapenem (ERT), $1(1,53 \%)$ a imipenem (IMP), 2 (3,07\%) a gentamicina (GEN), 1 (1,53\%) a tetraciclina (TET) e 3 (4,61\%) a sulfametoxazol-trimetoprim (SUT) (Quadro 6).

Dos 33 isolados de $E$. coli provenientes do ambiente prístino, $3(9,09 \%)$ foram resistentes aos antibióticos ampicilina, $3(9,09 \%)$ a cefalotina, $2(6,06 \%)$ a cefotetan, $2(6,06 \%)$ a cefoxitina, $2(6,06 \%)$ a gentamicina e $3(9,09 \%)$ a sulfametoxazol-trimetoprim.

Os resultados decorrentes do antibiograma revelaram que $26,15 \%$ dos isolados foram resitentes a pelo menos um antimicrobiano (tabela 3).

Tabela 3- Número e porcentagem de isolados de acordo com o perfil de suscetibilidade aos antimicrobianos.

\begin{tabular}{ll}
\hline Suscetibilidade & Total de isolados \\
\hline Sensíveis a todos antimicrobianos & $33(50,76 \%)$ \\
\hline Intermediário a 1 ou $>1$ antimicrobiano & $6(9,23 \%)$ \\
\hline Resistente a 1 antimicrobiano & $17(26,15 \%)$ \\
\hline Resistente a 2 antimicrobianos & $1(1,53 \%)$ \\
\hline Resistente a 3 antimicrobianos & $3(4,61 \%)$ \\
\hline Resistente a $>3$ antimicrobianos & $5(7,69 \%)$ \\
\hline Total & $\mathbf{6 5 ( 1 0 0 \% )}$ \\
\hline
\end{tabular}


Todos os isolados analisados (100\%) foram sensíveis aos antimicrobianos cefepima e ciprofloxacina.

Os testes fenotípicos para produção de enzimas $\beta$-lactamases foram feitos com base nos resultados obtidos no antibiograma. Os isolados que apresentaram halo reduzido para ceftazidima, cefotaxima e/ou aztreonam foi realizado o teste para produção de ESBL, por meio da técnica de aproximação de discos. Todos os isolados foram negativos para produção da enzima ESBL.

A enzima MBL foi detectada fenotipicamente em apenas um isolado de $E$. coli (FSP 62/00), entretanto, ao realizar a PCR para identificação dos genes de resistência, nenhum dos genes pesquisados foram identificados.

Usando o teste de combinação de discos, foi realizado o teste para produção de AmpC nos isolados que foram resistentes aos antibióticos cefoxitina e/ ou cefotetan $(\mathrm{n}=8)$. Todos os isolados $(100 \%)$ foram considerados como produtores de AmpC (figura 2). Entretanto, não foi verificada a presença de nenhum gene de resistência pesquisado. 


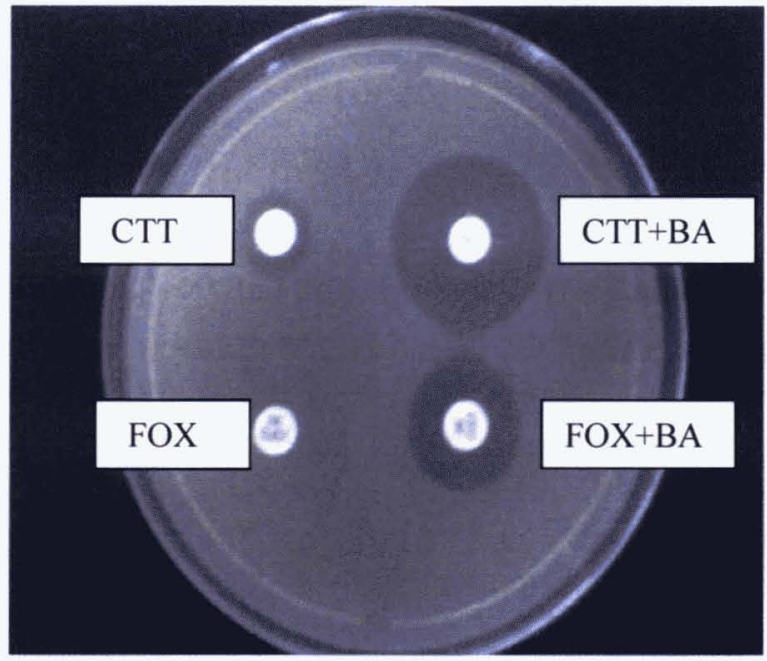

Figura 2: Detecção fenotípica da produção de AmpC utilizando a técnica de discos combinados. Discos contendo $30 \mu \mathrm{g}$ do antibiótico cefoxitina (FOX) e $30 \mu \mathrm{g}$ do antibiótico cefotetan (CTT) colocados a uma distância de 20 a $30 \mathrm{~mm}$ do disco contendo o inibidor ácido fenilborônico (BA). 
Quadro 6- Resultados do Antibiograma dos 65 isolados de E. coli de acordo com o ano de isolamento e origem.

\begin{tabular}{|c|c|c|c|c|c|c|c|c|c|c|c|c|c|c|c|c|}
\hline \multirow{2}{*}{$\begin{array}{c}\text { Ano de } \\
\text { isolamento }\end{array}$} & \multirow{2}{*}{ Origem } & \multirow{2}{*}{ Isolado } & \multicolumn{12}{|c|}{ Medidas dos halos de inibição (mm) } & \multirow[b]{2}{*}{ CIP } & \multirow[b]{2}{*}{ SUT } \\
\hline & & & $\mathbf{A M P}$ & CFL & CPM & CTX & CTT & FOX & CAZ & ATM & ERT & IMP & GEN & TET & & \\
\hline \multirow{21}{*}{1990} & \multirow{21}{*}{$\begin{array}{l}\text { Ambiente } \\
\text { pristino }\end{array}$} & $1022 / 09$ & $(28) \mathrm{S}$ & (24) S & (32) $S$ & (38) $S$ & $(32) S$ & $(24) S$ & (30) S & (30) S & (38) $S$ & (30) S & (24) S & (26) $S$ & (38) $S$ & (32) $\mathrm{S}$ \\
\hline & & $1023 / 09$ & (24) S & (26) $\mathrm{S}$ & (38) $S$ & (34) $S$ & (28) $\mathrm{S}$ & (30) $S$ & (36) $S$ & (36) $S$ & (32) $\mathrm{S}$ & (34) $\mathrm{S}$ & (22) $S$ & (20) $\mathrm{S}$ & (42) $S$ & (36) $\mathrm{S}$ \\
\hline & & $1024 / 09$ & (20) $S$ & (20) $S$ & (30) $S$ & (32) $\mathrm{S}$ & (32) $\mathrm{S}$ & (26) $S$ & (28) $\mathrm{S}$ & (30) $S$ & (30) $\mathrm{S}$ & (30) $\mathrm{S}$ & (20) S & (24) $S$ & (32) $\mathrm{S}$ & (30) $\mathrm{S}$ \\
\hline & & $1025 / 09$ & (24) S & (26) $S$ & (32) $\mathrm{S}$ & $(30) S$ & (28) $\mathrm{S}$ & (30) $\mathrm{S}$ & (32) $\mathrm{S}$ & (26) $S$ & (34) $\mathrm{S}$ & (36) $S$ & (14) 1 & (18) $\mathrm{S}$ & (32) $\mathrm{S}$ & (0) $R$ \\
\hline & & $1026 / 09$ & (22) $\mathrm{S}$ & (20) $S$ & (32) $S$ & (32) $\mathrm{S}$ & (28) $\mathrm{S}$ & (26) $S$ & (30) $\mathrm{S}$ & (34) $\mathrm{S}$ & (32) $\mathrm{S}$ & (32) $\mathrm{S}$ & (22) $\mathrm{S}$ & (26) $S$ & (42) $S$ & (0) $R$ \\
\hline & & $1027 / 09$ & (0) $\mathrm{R}$ & (10) $R$ & (26) $S$ & (32) $\mathrm{S}$ & (32) $\mathrm{S}$ & (18) $S$ & (24) $S$ & (26) $S$ & (32) $\mathrm{S}$ & (28) $S$ & (20) $S$ & (22) $\mathrm{S}$ & (30) $\mathrm{S}$ & (20) $\mathrm{S}$ \\
\hline & & $1028 / 09$ & (22) $\mathrm{S}$ & (20) $S$ & (28) $S$ & (28) S & (30) S & (28) $\mathrm{S}$ & (28) S & (30) $S$ & (32) $\mathrm{S}$ & (34) S & (20) S & (22) $\mathrm{S}$ & (36) $\mathrm{S}$ & (32) $\mathrm{S}$ \\
\hline & & $1029 / 09$ & (24) $\mathrm{S}$ & (24) S & (30)S & (32) $\mathrm{S}$ & $(30) S$ & (22) $\mathrm{S}$ & (26) $\mathrm{S}$ & (26) $S$ & (36) $\mathrm{S}$ & (24) $\mathrm{S}$ & (20) $\mathrm{S}$ & (20) $\mathrm{S}$ & (34) $\mathrm{S}$ & (28) $\mathrm{S}$ \\
\hline & & $1030 / 09$ & (24) $S$ & (16) I & (30) $S$ & (26) $S$ & (26) $S$ & (20) $S$ & (30) $S$ & (32) $\mathrm{S}$ & (30) $S$ & (30) $S$ & (22) $S$ & (22) $S$ & (34) $\mathrm{S}$ & (36) $\mathrm{S}$ \\
\hline & & $1031 / 09$ & (18) $\mathrm{S}$ & (18) $S$ & (30) $\mathrm{S}$ & (32) $\mathrm{S}$ & $(30) S$ & (26) $S$ & (26) $\mathrm{S}$ & (26) $S$ & (28) $S$ & (26) $S$ & (22) $\mathrm{S}$ & (18) $S$ & (34) $\mathrm{S}$ & (0) $R$ \\
\hline & & $1032 / 09$ & (24) $\mathrm{S}$ & (22) $\mathrm{S}$ & (36) $S$ & (32) $\mathrm{S}$ & (32) $\mathrm{S}$ & (32) $\mathrm{S}$ & (32) $\mathrm{S}$ & (36) $\mathrm{S}$ & (36) $S$ & (32) $\mathrm{S}$ & (24) $\mathrm{S}$ & (22) $\mathrm{S}$ & (38) $\mathrm{S}$ & (34) $\mathrm{S}$ \\
\hline & & $1033 / 09$ & (20) $S$ & (20) $S$ & (30) $\mathrm{S}$ & (34) $\mathrm{S}$ & (32) $\mathrm{S}$ & (22) $S$ & (28) $\mathrm{S}$ & (34) $\mathrm{S}$ & (32) $\mathrm{S}$ & (30) $S$ & (20) $S$ & (20) $S$ & (32) $\mathrm{S}$ & (34) $\mathrm{S}$ \\
\hline & & $1034 / 09$ & (22) $\mathrm{S}$ & (22) $S$ & (36) $S$ & (34) $\mathrm{S}$ & (34) S & (18) $S$ & (32) $\mathrm{S}$ & (34) $\mathrm{S}$ & (36) $S$ & (32) $S$ & (26) $S$ & (22) $\mathrm{S}$ & (38) $\mathrm{S}$ & (24) $\mathrm{S}$ \\
\hline & & $1035 / 09$ & (22) $\mathrm{S}$ & (24) S & (32) $\mathrm{S}$ & (34) $\mathrm{S}$ & (34) $\mathrm{S}$ & (24) $S$ & (30) $S$ & (30) $S$ & (20) $\mathrm{S}$ & (30) $S$ & (20) $S$ & (26) $S$ & (36) $S$ & (30) $\mathrm{S}$ \\
\hline & & $1036 / 09$ & (0) $R$ & (30) $\mathrm{S}$ & (36) $S$ & (30) $S$ & (20) $S$ & (30) $\mathrm{S}$ & (34) S & (36) $\mathrm{S}$ & (32) $\mathrm{S}$ & (30) S & (24) $\mathrm{S}$ & (26) $S$ & (42) $S$ & (38) $\mathrm{S}$ \\
\hline & & $1037 / 09$ & (24) S & (26) $S$ & (40) $S$ & (32) $\mathrm{S}$ & (16) $S$ & (26) $S$ & (36) $\mathrm{S}$ & (36) $S$ & (30) $S$ & (32) $\mathrm{S}$ & (24) $S$ & (26) $S$ & (42) $S$ & (38) $\mathrm{S}$ \\
\hline & & $1038 / 09$ & (22) $\mathrm{S}$ & (22) $\mathrm{S}$ & (34) $\mathrm{S}$ & (38) $\mathrm{S}$ & (36) $S$ & (22) $\mathrm{S}$ & (28) S & (32) $\mathrm{S}$ & (40) S & (30) $S$ & (20) $\mathrm{S}$ & (30) $S$ & (38) $S$ & (34) $\mathrm{S}$ \\
\hline & & $1039 / 09$ & (28) $\mathrm{S}$ & (34) $\mathrm{S}$ & (38) $S$ & (26) $\mathrm{S}$ & $(30) S$ & (34) $\mathrm{S}$ & (36) $\mathrm{S}$ & (42) $\mathrm{S}$ & (38) $\mathrm{S}$ & (36) $\mathrm{S}$ & (8) $R$ & (26) $\mathrm{S}$ & (40) $S$ & (38) $\mathrm{S}$ \\
\hline & & $1040 / 09$ & (20) $S$ & (18) $S$ & (32) $S$ & (30) $S$ & (22) $S$ & (16) I & (30) $\mathrm{S}$ & (32) $S$ & (32) $S$ & (32) $S$ & (20) $S$ & (24) S & (36) $S$ & (30) $\mathrm{S}$ \\
\hline & & $1042 / 09$ & (22) S & (18) $\mathrm{S}$ & (36) $S$ & (30) $\mathrm{S}$ & (30) S & (30) S & (30) S & (32) $\mathrm{S}$ & (30) $S$ & (30) S & (22) $\mathrm{S}$ & (26) $S$ & (40) S & (36) $\mathrm{S}$ \\
\hline & & $3 / 09$ & (20) S & 18) $S$ & (34)S & (32) S & (36) $S$ & (28) S & (28) S & 32) $\mathrm{S}$ & (38) S & (30) S & 22) $\mathrm{S}$ & 26) $S$ & (38) S & \\
\hline
\end{tabular}

AMP: Ampicilina; CFL: Cefalotina; CFM: Cefepime; CTX: Cefotaxima; CTT: Cefotetan; FOX: Cefoxitina; CAZ: Ceftazidima; ATM: Aztreonam; ERT: Ertapenem; IMP: Imipenem; GEN: Gentamicina; TET: Tetraciclina; CIP: Ciprofloxacina; SUT: Sulfametoxazol-trimetoprim R: Resistente; S: Sensivel; I: Intermediário. 
Quadro 6- Resultados do Antibiograma dos 65 isolados de E. coli de acordo com o ano de isolamento e origem.(Continuação)

\begin{tabular}{|c|c|c|c|c|c|c|c|c|c|c|c|c|c|c|c|c|}
\hline \multirow{2}{*}{$\begin{array}{c}\text { Ano de } \\
\text { isolamento }\end{array}$} & \multirow{2}{*}{ Origem } & \multirow{2}{*}{ Isolado } & \multicolumn{12}{|c|}{ Medidas dos halos de inibição (mm) } & \multirow[b]{2}{*}{ CIP } & \multirow[b]{2}{*}{ SUT } \\
\hline & & & AMP & CFL & CPM & CTX & CTT & FOX & CAZ & ATM & ERT & IMP & GEN & TET & & \\
\hline \multirow{12}{*}{1990} & \multirow{12}{*}{$\begin{array}{c}\text { Ambiente } \\
\text { pristino }\end{array}$} & $1044 / 09$ & (20) $S$ & (16) I & (38) $\mathrm{S}$ & (26) $\mathrm{S}$ & (26) $\mathrm{S}$ & (28) $\mathrm{S}$ & (36) $\mathrm{S}$ & (36) $\mathrm{S}$ & (34) $S$ & (34) $\mathrm{S}$ & (22) $\mathrm{S}$ & (26) $\mathrm{S}$ & (42) S & (36) $\mathrm{S}$ \\
\hline & & $1045 / 09$ & (24) S & (30) $\mathrm{S}$ & (38) $\mathrm{S}$ & (32) $\mathrm{S}$ & (26)S & (26) $\mathrm{S}$ & (34) $\mathrm{S}$ & (38) $\mathrm{S}$ & (20) $\mathrm{S}$ & (32) $\mathrm{S}$ & (20) $\mathrm{S}$ & (26) $S$ & (38) $\mathrm{S}$ & (36) $\mathrm{S}$ \\
\hline & & $1046 / 09$ & (28) $\mathrm{S}$ & (24) $\mathrm{S}$ & (36) $\mathrm{S}$ & (32) $\mathrm{S}$ & (28) $\mathrm{S}$ & (26) $\mathrm{S}$ & (30) $S$ & (32) $\mathrm{S}$ & (32) $\mathrm{S}$ & (28) $\mathrm{S}$ & (20) $\mathrm{S}$ & (22) $\mathrm{S}$ & (38) $\mathrm{S}$ & (32) $\mathrm{S}$ \\
\hline & & $1047 / 09$ & (20) $S$ & (22) $\mathrm{S}$ & (32) $\mathrm{S}$ & (38) $\mathrm{S}$ & (32) $\mathrm{S}$ & (18) $\mathrm{S}$ & (32) $\mathrm{S}$ & (30) $\mathrm{S}$ & (36) $\mathrm{S}$ & (28) $\mathrm{S}$ & (20) $\mathrm{S}$ & (28) $\mathrm{S}$ & (38) $\mathrm{S}$ & (32) $\mathrm{S}$ \\
\hline & & $1048 / 09$ & (18) $\mathrm{S}$ & (24) $S$ & (36) $\mathrm{S}$ & (38) $\mathrm{S}$ & (32) $\mathrm{S}$ & (24) $\mathrm{S}$ & (28) $\mathrm{S}$ & (34) $\mathrm{S}$ & (34) $\mathrm{S}$ & (32) $\mathrm{S}$ & (22) $\mathrm{S}$ & (26) $S$ & (36) $S$ & (36) $\mathrm{S}$ \\
\hline & & $1049 / 09$ & (12) $R$ & (8) $R$ & (26) $\mathrm{S}$ & (30) $\mathrm{S}$ & (8) $R$ & (8) $R$ & (28) $\mathrm{S}$ & (30) $\mathrm{S}$ & (32) $\mathrm{S}$ & (30) $\mathrm{S}$ & (12)R & (24) S & (38) $\mathrm{S}$ & (32) $\mathrm{S}$ \\
\hline & & $1050 / 09$ & (16) I & (12) $R$ & (30) $\mathrm{S}$ & (28) S & (8) $R$ & (12) $R$ & (28) $\mathrm{S}$ & (30) $S$ & (30) $S$ & (28) $\mathrm{S}$ & (20) $\mathrm{S}$ & (20) S & (40) $\mathrm{S}$ & (34) $\mathrm{S}$ \\
\hline & & $1051 / 09$ & (24) S & (26) $S$ & (38) $\mathrm{S}$ & (32) $\mathrm{S}$ & (26) $S$ & (26) $\mathrm{S}$ & (34) $\mathrm{S}$ & (38) $\mathrm{S}$ & (26) $S$ & (32) $\mathrm{S}$ & (20) $S$ & (24) $\mathrm{S}$ & (42) $\mathrm{S}$ & (36) $\mathrm{S}$ \\
\hline & & $1052 / 09$ & (20) $S$ & (18) $S$ & (32) $\mathrm{S}$ & (34) S & (30) $S$ & (24) S & (26) $\mathrm{S}$ & (30) $\mathrm{S}$ & (36) $\mathrm{S}$ & (30) $\mathrm{S}$ & (18) $S$ & (22) $\mathrm{S}$ & (38) $\mathrm{S}$ & (32) $\mathrm{S}$ \\
\hline & & $1053 / 09$ & (20) $S$ & (18) $\mathrm{S}$ & (30) $S$ & (26) $\mathrm{S}$ & (26) $\mathrm{S}$ & (18) $\mathrm{S}$ & (28) $\mathrm{S}$ & (32) $\mathrm{S}$ & (28) $\mathrm{S}$ & (30) $S$ & (20) $S$ & (20) $S$ & (36) $S$ & (26) $\mathrm{S}$ \\
\hline & & $1054 / 09$ & (20) $S$ & (16) I & (32) $\mathrm{S}$ & (26) S & (26) $\mathrm{S}$ & (24) S & (30) $\mathrm{S}$ & (30) $\mathrm{S}$ & (32) $\mathrm{S}$ & (34) $\mathrm{S}$ & (14) I & (22) S & (36) $\mathrm{S}$ & (26) $\mathrm{S}$ \\
\hline & & $1057 / 09$ & (22) $\mathrm{S}$ & (22) $\mathrm{S}$ & (32) $\mathrm{S}$ & (34) $\mathrm{S}$ & (26) $S$ & (24) $\mathrm{S}$ & (28) $\mathrm{S}$ & (32) S & (26) $\mathrm{S}$ & (30) $\mathrm{S}$ & $(22) \mathrm{S}$ & (24) S & (42) S & (32) $\mathrm{S}$ \\
\hline \multirow{9}{*}{2000} & \multirow{9}{*}{$\begin{array}{l}\text { Água } \\
\text { mineral }\end{array}$} & $1 / 00$ & (10) $R$ & (32) $\mathrm{S}$ & (38) $\mathrm{S}$ & (38) $\mathrm{S}$ & (32) $\mathrm{S}$ & (30) $\mathrm{S}$ & (36) $\mathrm{S}$ & (42) $\mathrm{S}$ & (36) $\mathrm{S}$ & (34) $\mathrm{S}$ & (20) $\mathrm{S}$ & (28) $\mathrm{S}$ & (36) $\mathrm{S}$ & (32) $\mathrm{S}$ \\
\hline & & $2 / 00$ & (12) $R$ & (28) $S$ & (36) $\mathrm{S}$ & (38) $\mathrm{S}$ & (32) $S$ & (28) $\mathrm{S}$ & (32) S & (36) $\mathrm{S}$ & (34) S & (30) $\mathrm{S}$ & (20) $\mathrm{S}$ & (26) S & (34) S & (30) $\mathrm{S}$ \\
\hline & & $12 / 00$ & (10) $R$ & (10) $R$ & (36) $\mathrm{S}$ & (30) $\mathrm{S}$ & (32) $S$ & (0) $R$ & (30) $\mathrm{S}$ & (36) $\mathrm{S}$ & (36) $\mathrm{S}$ & (26) S & (20) $S$ & (24) S & (36) $\mathrm{S}$ & (30) $\mathrm{S}$ \\
\hline & & $27 / 00$ & (0) $R$ & (20) $S$ & (38) $\mathrm{S}$ & (38) $\mathrm{S}$ & (26) $S$ & (16) I & (32) $\mathrm{S}$ & (38) $\mathrm{S}$ & (36) $\mathrm{S}$ & (32) $\mathrm{S}$ & (20) $\mathrm{S}$ & (26) S & (36) $\mathrm{S}$ & (30) $\mathrm{S}$ \\
\hline & & $30 / 00$ & (0) $R$ & (26) $\mathrm{S}$ & (34) $\mathrm{S}$ & (32) $\mathrm{S}$ & (26) $\mathrm{S}$ & (24) S & (30) $\mathrm{S}$ & (32) $\mathrm{S}$ & (26) $\mathrm{S}$ & (34) S & (18) S & (24) S & (30) $\mathrm{S}$ & $(28) \mathrm{S}$ \\
\hline & & $31 / 00$ & (0) $R$ & (24) S & (32) $\mathrm{S}$ & (34) S & (30) $\mathrm{S}$ & (24) S & (30) $\mathrm{S}$ & (30) $\mathrm{S}$ & (36) $\mathrm{S}$ & (22) I & (18) $\mathrm{S}$ & (22) S & (34) S & (30) $\mathrm{S}$ \\
\hline & & $38 / 00$ & (8) $R$ & (0) $R$ & (28) $\mathrm{S}$ & (0) $R$ & (10) $R$ & (0) $R$ & (10) $R$ & (16) $R$ & (28) $\mathrm{S}$ & (26) S & (18) $\mathrm{S}$ & $(20) \mathrm{S}$ & (26) $\mathrm{S}$ & (26) $\mathrm{S}$ \\
\hline & & $62 / 00$ & (10) $R$ & (0) $R$ & (26) $S$ & (10) $R$ & (0) $R$ & (0) $R$ & (14) $R$ & (20) I & (14) $R$ & (16) $R$ & (18) $\mathrm{S}$ & (22) $\mathrm{S}$ & (30) $\mathrm{S}$ & (26) $\mathrm{S}$ \\
\hline & & $67 / 00$ & (0) R & (14) $R$ & (36) $\mathrm{S}$ & (32) $\mathrm{S}$ & (14) I & (0) $R$ & (30) S & (36) $\mathrm{S}$ & (36) $\mathrm{S}$ & (30) S & (20) S & (24) S & (36) $\mathrm{S}$ & (30) $S$ \\
\hline
\end{tabular}

AMP: Ampicilina; CFL: Cefalotina; CFM: Cefepime; CTX: Cefotaxima; CTT: Cefotetan; FOX: Cefoxitina; CAZ: Ceftazidima; ATM: Aztreonam; ERT: Ertapenem; IMP: Imipenem; GEN: Gentamicina; TET: Tetraciclina; CIP: Ciprofloxacina; SUT: Sulfametoxazol-trimetoprim R: Resistente; S: Sensivel; I: Intermediário. 
Quadro 6- Resultados do Antibiograma dos 65 isolados de $E$. coli de acordo com o ano de isolamento e origem.(Continuação)

\begin{tabular}{|c|c|c|c|c|c|c|c|c|c|c|c|c|c|c|c|c|}
\hline \multirow{2}{*}{$\begin{array}{c}\text { Ano de } \\
\text { isolamento }\end{array}$} & \multirow{2}{*}{ Origem } & \multirow{2}{*}{ Isolado } & \multicolumn{12}{|c|}{ Medidas dos halos de inibição (mm) } & \multirow[b]{2}{*}{ CIP } & \multirow[b]{2}{*}{ SUT } \\
\hline & & & AMP & CFL & CPM & CTX & CTT & FOX & CAZ & ATM & ERT & IMP & GEN & TET & & \\
\hline 2000 & Água min & $70 / 00$ & (0) $\mathbf{R}$ & (14) $R$ & (34) $\mathrm{S}$ & (12) $R$ & (8) $R$ & (0) $R$ & (14) $R$ & (18) I & (24) $\mathrm{S}$ & (26) $S$ & (20) $S$ & (24) S & (32) $\mathrm{S}$ & (30) $\mathrm{S}$ \\
\hline \multirow{5}{*}{2002} & \multirow{5}{*}{$\begin{array}{l}\text { Queijo } \\
\text { minas }\end{array}$} & $1392 / 0280$ & (18) $\mathrm{S}$ & (22) $\mathrm{S}$ & (38) $\mathrm{S}$ & (38) $\mathrm{S}$ & (32) $\mathrm{S}$ & (24) $\mathrm{S}$ & (32) $\mathrm{S}$ & (38) $\mathrm{S}$ & (38) $\mathrm{S}$ & (34) $\mathrm{S}$ & (20) $\mathrm{S}$ & (26) $\mathrm{S}$ & (36) $\mathrm{S}$ & (32) $\mathrm{S}$ \\
\hline & & $1400 / 0286$ & (22) $\mathrm{S}$ & (20) $\mathrm{S}$ & (34) $\mathrm{S}$ & (34) $\mathrm{S}$ & (28) $\mathrm{S}$ & (24) $\mathrm{S}$ & (30) $\mathrm{S}$ & (36) $\mathrm{S}$ & (32) $\mathrm{S}$ & (30) $\mathrm{S}$ & (20) $\mathrm{S}$ & (20) $\mathrm{S}$ & (32) $\mathrm{S}$ & (32) $\mathrm{S}$ \\
\hline & & $1402 / 0287$ & (26) $S$ & (26) $\mathrm{S}$ & (32) $\mathrm{S}$ & (32) $\mathrm{S}$ & (32) $\mathrm{S}$ & (26) $\mathrm{S}$ & (30) $S$ & (36) $\mathrm{S}$ & (30) $\mathrm{S}$ & (32) $\mathrm{S}$ & (20) $\mathrm{S}$ & (24) S & (32) S & (32) $\mathrm{S}$ \\
\hline & & $1424 / 02105$ & (20) S & (20) $\mathrm{S}$ & (30) $\mathrm{S}$ & (30) $\mathrm{S}$ & (28) $\mathrm{S}$ & (20) $\mathrm{S}$ & (26) $\mathrm{S}$ & (22) $\mathrm{S}$ & (34) $\mathrm{S}$ & (28) $\mathrm{S}$ & (16) $S$ & (18) $\mathrm{S}$ & (28) $\mathrm{S}$ & (26) $\mathrm{S}$ \\
\hline & & $1502 / 02$ & (24) $\mathrm{S}$ & (22) $\mathrm{S}$ & (36) $\mathrm{S}$ & (32) $\mathrm{S}$ & (28) $\mathrm{S}$ & (24) $\mathrm{S}$ & (30) $\mathrm{S}$ & (36) $\mathrm{S}$ & (32) $\mathrm{S}$ & (30) $\mathrm{S}$ & (20) $\mathrm{S}$ & (26) $\mathrm{S}$ & (32) $\mathrm{S}$ & (30) $\mathrm{S}$ \\
\hline \multirow{8}{*}{2003} & \multirow{8}{*}{$\begin{array}{c}\text { Fezes de } \\
\text { bovinos }\end{array}$} & $1041 / 03$ & (16) I & (8) $R$ & (36) $S$ & (32) $\mathrm{S}$ & (32) $\mathrm{S}$ & (24) $\mathrm{S}$ & (32) $\mathrm{S}$ & (32) $\mathrm{S}$ & (32) $\mathrm{S}$ & (28) $\mathrm{S}$ & (16) $\mathrm{S}$ & (22) S & (32) $\mathrm{S}$ & (32) S \\
\hline & & $1047 / 03$ & (22) $\mathrm{S}$ & (18) $\mathrm{S}$ & (30) $\mathrm{S}$ & (28) $\mathrm{S}$ & (30) $\mathrm{S}$ & (24) $\mathrm{S}$ & (26) $\mathrm{S}$ & (22) $\mathrm{S}$ & (32) $\mathrm{S}$ & (30) $\mathrm{S}$ & (18) $\mathrm{S}$ & (22) $\mathrm{S}$ & (30) $\mathrm{S}$ & (28) $\mathrm{S}$ \\
\hline & & $1048 / 03$ & (20) $S$ & (22) $S$ & (32) $\mathrm{S}$ & (32) $\mathrm{S}$ & (30) $S$ & (24) $S$ & (30) $\mathrm{S}$ & (26) $S$ & (36) $S$ & (30) $\mathrm{S}$ & (20) $S$ & (20) $\mathrm{S}$ & (30) $\mathrm{S}$ & (28) $\mathrm{S}$ \\
\hline & & $1053 / 03$ & (14) I & (14) $R$ & (32) $\mathrm{S}$ & (26) $\mathrm{S}$ & (26) $\mathrm{S}$ & (24) S & (26) $\mathrm{S}$ & (30) $S$ & (30) $\mathrm{S}$ & (26) $S$ & (18) $\mathrm{S}$ & (22) S & (28) $\mathrm{S}$ & (30) $\mathrm{S}$ \\
\hline & & $1059 / 03$ & (14) I & (18) $\mathrm{S}$ & (32) $\mathrm{S}$ & (32) $\mathrm{S}$ & (30) $\mathrm{S}$ & (24) $\mathrm{S}$ & (26) $\mathrm{S}$ & (32) $\mathrm{S}$ & (28) $\mathrm{S}$ & (26) $\mathrm{S}$ & (20) $\mathrm{S}$ & (18) $\mathrm{S}$ & (36) $\mathrm{S}$ & (32) $\mathrm{S}$ \\
\hline & & $1060 / 03$ & (18) $\mathrm{S}$ & (18) $\mathrm{S}$ & (32) $\mathrm{S}$ & (32) $\mathrm{S}$ & (32) $\mathrm{S}$ & (24) $\mathrm{S}$ & (26) $S$ & (30) $\mathrm{S}$ & (36) $\mathrm{S}$ & (34) $\mathrm{S}$ & (20) $\mathrm{S}$ & (22) S & (26) S & (30) $\mathrm{S}$ \\
\hline & & $1067 / 03$ & (16) I & (18) $S$ & (36) $\mathrm{S}$ & (34) $S$ & (32) S & (20) $S$ & (32) $\mathrm{S}$ & (36) $\mathrm{S}$ & (32) $\mathrm{S}$ & (32) $\mathrm{S}$ & (20) $\mathrm{S}$ & (20) S & (32) $\mathrm{S}$ & (30) $\mathrm{S}$ \\
\hline & & $1073 / 03$ & (22) $\mathrm{S}$ & (18) $\mathrm{S}$ & (36) $S$ & (34) $\mathrm{S}$ & (34) $\mathrm{S}$ & (18) $S$ & (32) $\mathrm{S}$ & (36) $\mathrm{S}$ & (36) $\mathrm{S}$ & (36) $\mathrm{S}$ & (20) $\mathrm{S}$ & (22) $\mathrm{S}$ & (26) $\mathrm{S}$ & (30) $\mathrm{S}$ \\
\hline \multirow{3}{*}{2005} & \multirow{3}{*}{ Clínica } & $521 / 08$ & (22) $\mathrm{S}$ & (20) S & (30) $\mathrm{S}$ & (30) $\mathrm{S}$ & (32) $\mathrm{S}$ & (26) $\mathrm{S}$ & (26) S & (32) $\mathrm{S}$ & (32) $\mathrm{S}$ & (32) $\mathrm{S}$ & (18) $\mathrm{S}$ & (20) $\mathrm{S}$ & (22) $\mathrm{S}$ & (26) $\mathrm{S}$ \\
\hline & & $527 / 08$ & (22) S & (18) $\mathrm{S}$ & (30) $\mathrm{S}$ & (32) $\mathrm{S}$ & (30) $\mathrm{S}$ & (26) $\mathrm{S}$ & (26) $\mathrm{S}$ & (28) $\mathrm{S}$ & (28) $\mathrm{S}$ & (30) $\mathrm{S}$ & (18) $\mathrm{S}$ & (24) $\mathrm{S}$ & (28) $\mathrm{S}$ & (30) $\mathrm{S}$ \\
\hline & & $530 / 08$ & (0) $\mathbf{R}$ & (0) $R$ & (30) S & (14) $R$ & (10) $R$ & (10) $R$ & (10) $R$ & (12) $R$ & (30) S & (28) $\mathrm{S}$ & (20) $\mathrm{S}$ & (0) $\mathbf{R}$ & (24) S & (22) $\mathrm{S}$ \\
\hline
\end{tabular}

AMP: Ampicilina; CFL: Cefalotina; CFM: Cefepime; CTX: Cefotaxima; CTT: Cefotetan; FOX: Cefoxitina; CAZ: Ceftazidima; ATM: Aztreonam; ERT: Ertapenem; IMP: Imipenem; GEN: Gentamicina; TET: Tetraciclina; CIP: Ciprofloxacina; SUT: Sulfametoxazol-trimetoprim R: Resistente; S: Sensível; I: Intermediário. 
Quadro 6- Resultados do Antibiograma dos 65 isolados de $E$. coli de acordo com o ano de isolamento e origem.(Continuação)

\begin{tabular}{|c|c|c|c|c|c|c|c|c|c|c|c|c|c|c|c|c|}
\hline \multirow{2}{*}{$\begin{array}{c}\text { Ano de } \\
\text { isolamento }\end{array}$} & \multirow{2}{*}{ Origem } & \multirow{2}{*}{ Isolado } & \multicolumn{12}{|c|}{ Medidas dos halos de inibição (mm) } & \multirow[b]{2}{*}{ CIP } & \multirow[b]{2}{*}{ SUT } \\
\hline & & & AMP & CFL & CPM & CTX & CTT & FOX & $\mathbf{C A Z}$ & ATM & ERT & IMP & GEN & TET & & \\
\hline \multirow{6}{*}{2006} & \multirow{6}{*}{$\begin{array}{l}\text { Água } \\
\text { tratada }\end{array}$} & $3 / 06$. & (20) $S$ & (14) $\mathbf{R}$ & (36) $S$ & (32) $\mathrm{S}$ & (32) $\mathrm{S}$ & (22) $\mathrm{S}$ & (32) $\mathrm{S}$ & (36) $\mathrm{S}$ & (34) $\mathrm{S}$ & (34) $\mathrm{S}$ & (20) $\mathrm{S}$ & (26) $S$ & (34) $S$ & (36) $\mathrm{S}$ \\
\hline & & $15 / 06$ & (18) $S$ & (14) $\mathbf{R}$ & (34) $\mathrm{S}$ & (32) $\mathrm{S}$ & (30) $\mathrm{S}$ & (18) $S$ & (30) $S$ & (30) $\mathrm{S}$ & (36) $\mathrm{S}$ & (32) $S$ & (18) $\mathrm{S}$ & (24) $S$ & (32) $S$ & (32) $\mathrm{S}$ \\
\hline & & 16/06. & (26) $\mathrm{S}$ & (26) $\mathrm{S}$ & (38) $\mathrm{S}$ & (38) $S$ & (34) S & (28) $\mathrm{S}$ & (34) $\mathrm{S}$ & (38) $\mathrm{S}$ & (38) $\mathrm{S}$ & (32) $\mathrm{S}$ & (20) $S$ & (18) $\mathrm{S}$ & (38) $\mathrm{S}$ & (28) $\mathrm{S}$ \\
\hline & & 18/06. & (14) I & (14) $R$ & (30) $S$ & (30) $S$ & (26) S & (28) $\mathrm{S}$ & (24) S & (28) $\mathrm{S}$ & (30) $\mathrm{S}$ & (30) $S$ & (20) $S$ & (20) S & (32) $\mathrm{S}$ & (26) $\mathrm{S}$ \\
\hline & & $50 / 06$ & (0) $R$ & (22) S & (36) $S$ & (36) $S$ & (32) $\mathrm{S}$ & (30) $S$ & (30) $\mathrm{S}$ & (34) $\mathrm{S}$ & (36) $\mathrm{S}$ & (32) $\mathrm{S}$ & (20) $\mathrm{S}$ & (24) S & (36) $S$ & (28) $\mathrm{S}$ \\
\hline & & $51 / 06$ & (0) $\mathbf{R}$ & (30) S & (40) $\mathrm{S}$ & (38) $\mathrm{S}$ & (38) $\mathrm{S}$ & (34) $\mathrm{S}$ & (36) $\mathrm{S}$ & (42) $\mathrm{S}$ & (42) $\mathrm{S}$ & (38) $\mathrm{S}$ & (18) S & (12) I & $(42) S$ & (40) $S$ \\
\hline
\end{tabular}




\section{DISCUSSÃO}

Escherichia coli é uma bactéria comensal pertencente à microbiota intestinal de humanos e de animais de sangue quente. Porém, tem sido associada à meningite neonatal, sepse, infecções do trato urinário e gastroenterite (KAPER et al., 2004).

Com base no levantamento bibliográfico realizado pode-se notar que são poucos os estudos de genes de resistência feitos com cepas comensais de $E$. coli, as quais poderiam constituir reservatório de genes de resistência.

\subsection{GRUPO FILOGENÉTICO}

De acordo com a literatura isolados de $E$. coli podem ser agrupados em 4 grupos filogenéticos A,B1, B2 e D, por meio da PCR (CLERMONT et al., 2000).

Os resultados do presente estudo demonstraram que o grupo $\mathrm{B} 1$ foi o mais frequente entre as amostras. Nossos resultados corroboram com o trabalho realizado por CARLOS et al. (2010), os autores isolaram $E$. coli de fezes de humanos, bovinos, frangos, suínos e caprinos com a finalidade de analisar a distribuição do grupo filogenético. Verificaram que o grupo B1 foi o de maior ocorrência.

No presente trabalho os isolados de $E$. coli provenientes de água mineral pertenceram ao grupo filogenético A. Nossos dados corroboram com o trabalho realizado por Orsi et al. (2007), que estudaram 49 cepas de $E$. coli isoladas de diferentes amostras de água de consumo humano e, relataram que $57 \%$ das $E$. coli isoladas de água mineral pertenceram ao grupo A. Os isolados de $E$. coli comensal são usualmente do grupo A e B1 (CLERMONT et al., 2000). 
No presente estudo alguns isolados de $E$. coli oriundos de amostras de água tratada pertenceram aos grupos B2 e D. Esses resultados sugerem a possibilidade de ter ocorrido contaminação fecal da amostra e que o processo de tratamento não foi suficiente para eliminar bactérias patogênicas.

Sabe-se que cepas pertencentes ao grupo B2 são patogênicas e frequentemente associadas a infecções extraintestinais em humanos (DURIEZ et al., 2001; TIBA et al., 2009; MOLINA-LÓPEZ et al., 2011; BENGTSSON et al., 2012), enquanto que o grupo filogenético $\mathrm{D}$ inclui cepas patogênicas tais como $\mathrm{O} 157: \mathrm{H} 7$, as quais são altamente virulentas e podem causar diarréia, síndrome hemolítica urêmica e colite hemorrágica, porém necessitam da presença e expressão dos genes de virulência. (CLERMONT et al., 2000; KAPER et al., 2004).

No presente estudo dois isolados oriundos de infecção hospitalar pertenceram ao grupo B1. Esse resultado sugere que possivelmente ocorreu uma translocação bacteriana (BERG, 1995), pois, E. coli permanece colonizadora, confinada ao lúmen intestinal, entretanto em indivíduos debilitados ou imunocomprometidos, ou ainda quando as barreiras do trato gastrointestinal são violadas, mesmo as espécies não patogênicas podem causar infeç̧ões migrando para corrente sanguínea (NATARO e KAPER,1998).

\subsection{TESTE DE SENSIBLIDADE AOS ANTIMICROBIANOS}

A utilização de compostos com atividades antimicrobianas gerou grande avanço em relação à prevenção e ao tratamento de doenças infecciosas. Entretanto, o uso generalizado dessas substâncias tem ocasionado o desenvolvimento de 
microrganismos resistentes aos antimicrobianos (MONTELLI e SADATSUNE, 2001).

Diante do aumento de microrganismos resistentes aos antimicrobianos, principalmente à classe de $\beta$-lactâmicos, diversos estudos têm sido realizados com isolados de $E$. coli de diferentes tipos de amostras, tendo como finalidade a identificação fenotípica do perfil de suscetibilidade aos antimicrobianos (ABONG'O et al., 2008; SALIH et al., 2009; ZANELLA et al., 2010; KOO e WOO, 2011; LUO et al., 2011).

E. coli pode ser facilmente disseminada em diferentes ecossistemas por meio da cadeia alimentar e água (ALEXANDER et al., 2010). A presença de bactérias entéricas no ambiente aquático pode representar risco a Saúde Pública, principalmente, se esses microrganismos forem resistentes aos antimicrobianos (VIGNAROLI et al., 2012). No presente trabalho foi observada a resistência aos antimicrobianos em isolados de $E$. coli oriundos de amostras de água mineral.

Antimicrobianos beta-lactâmicos e fluoroquinolonas são importantes classes de medicamentos utilizados no tratamento de infecções causadas por Enterobacteriaceae (PITOUT, 2008). Nos últimos anos tem sido observada a emergência de mecanismos de resistência contra esses antimicrobianos em Enterobacteriaceae (TAUSOVA et al., 2012).

No presente trabalho, todos os isolados foram sensíveis aos antimicrobianos cefepima e ciprofloxacina enquanto que GOUSIA et al. (2011) relataram apenas $14,6 \%$ dos isolados sensíveis a ciprofloxacina. 
Os resultados demonstraram que $98,46 \%$ dos isolados foram sensíveis a imipenem e a ertapenem, esses dados corroboram com as observações feitas por MENEZES et al. 2007 a respeito da eficácia do antimicrobiano ertapenem no tratamento de infecções causadas por Enterobacteriaceae.

No presente estudo, dentre as cepas de ambiente pristino $24,24 \%(8 / 33)$ apresentaram resistência aos antimicrobianos ampicilina, cefalotina, cefotetan, cefoxitina, gentamicina e sulfametoxazol-trimetoprim. Esses resultados não eram esperados, devido essas cepas terem sido isoladas de um ambiente que não havia sofrido nenhum tipo de ação antrópica, na época. Nossos resultados corroboram com o trabalho realizado por LIMA-BITTENCOURT et al. 2007 com Enterobacteriaceae isoladas de água doce (ambiente pristino), no qual verificaram o padrão de resistência antimicrobiana. Os isolados foram resistentes principalmente a ampicilina

\section{$5.4 \beta$-LACTAMASES (ESBL, AmpC e MBL)}

Enterobacteriaceae produtoras de $\beta$-lactamases de espectro estendido tem emergido tanto no ambiente hospitalar como na comunidade como um importante agente de infecções (ROSSI, 2011).

Não foi verificada a produção de ESBL nos isolados estudados. No trabalho realizado por EGEA et al. (2011) apenas um isolado de $E$. coli foi positivo para a produção de ESBL. Estudiosos têm relatado a produção de ESBL principalmente em Klebsiella pneumoniae (OLIVEIRA et al., 2009). 
DESHPANDE et al. (2006) relatam que as Enterobacteriaceae com o perfil fenotípico de ESBL, mas negativo ao realizar o teste confirmatório, são potenciais candidatos a produção da enzima AmpC. Esse perfil fenotípico pode ser observado no presente trabalho, pois alguns isolados apresentaram diminuição nos halos para os ceftazidima, cefotaxima e/ou aztreonam, porém, ao realizarmos o teste para produção da enzima ESBL, o mesmo foi negativo e positivo no teste confirmatório para a produção da enzima AmpC.

As $\beta$-lactamases do tipo AmpC foram descritas inicialmente como enzimas de origem cromossômica constitutivas em espécies da família Enterobacteriaceae, tais como Enterobacter spp, Citrobacter spp, Serratia spp, Morganella morganii $e$ Hafnia alvei e são tipicamente induzidas por antimicrobianos beta-lactâmicos tais como cefoxitina e imipenem (LIVERMORE, 1995; BUSH e JACOBY, 2010).

Bactérias com superexpressão de $\mathrm{AmpC}$ constituem uma das principais preocupações no ambiente hospitalar, pois esses microrganismos são geralmente resistentes a todos os antimicrobianos $\beta$-lactâmicos, exceto para cefepima, cefpiroma e carbapenêmicos. A superexpressão constitutiva de $\beta$-lactamases AmpC em bactérias Gram negativas ocorre por meio da desregulação do gene $a m p C$ cromossômico ou por aquisição de $a m p C$ plasmidial (PÉREZ-PÉREZ e HANSON ,2002).

Uma diferença importante de $E$. coli e Shigella spp.em relação às outras enterobactérias e Pseudomonas aeruginosa, que possuem gene ampC cromossômico,é que a hiperprodução de beta-lactamase AmpC, nos dois primeiros 
gêneros, não é induzida, e sim em decorrência de mutações ocorridas nos promotores que codificam as enzimas ( COUNDRON e THOMSON, 2000; PEREZ E PEREZ e HANSON, 2002).

No presente trabalho, a deteç̧ão de enzimas AmpC foi feita por meio da técnica de discos combinados, com o inibidor ácido fenilborônico. Outros estudos também descreveram a utilização desta técnica na deteç̧ão de AmpC (TENOVER et al., 2009; SINGTOHIN et al., 2010).

Todos os isolados de E. coli produtores de AmpC pertenceram ao grupo filogenético A. Nossos dados corroboram com o estudo de CORVEC et al. (2007) realizado com isolados clínicos de E.coli.

Quanto a presença dos genes de resistência, os resultados obtidos demonstraram que não houve amplificação de genes $a m p C$, possivelmente a resistência à cefamicinas envolve outros mecanismos de resistência, como a perda de porina e/ou aumento da atividade de bomba de efluxo (JACOBY, 2009).

Nossos resultados corroboram com o estudo de SILVA-DIAS et al. (2008) que verificaram a produção de $A m p C$ em isolados clínicos de $E$. coli e não detectaram os genes.

Dentre as diferentes classes de beta-lactamases, as carbapenemases pertencem à família mais versátil pela ampla atividade hidrolítica à maioria dos antimicrobianos beta-lactâmicos (QEENAN e BUSH, 2007). 
As carbapenemases pertencem, na sua maioria, a duas classes moleculares, as carbapenemases de classe A e as metalo- $\beta$-lactamases de classe B de Ambler. As oxacilinases, $\beta$-lactamases de classe $D$, também hidrolisam antimicrobianos carbapenêmicos, porém sua prevalência em Enterobacteriaceae é baixa, sendo frequentemente relatadas em Acinetobacter spp.(WALTHER-RASMUSSEN e HOIBY, 2007; GULMEZ et al., 2008).

As metalo- $\beta$-lactamases, estão emergindo mundialmente em bactérias Gram negativas, principalmente em Pseudomonas aeruginosa, Acinetobacter sp e Enterobacteriaceae. A emergência dessas enzimas compromete o tratamento efetivo de infecções causadas por esses microrganismos, uma vez que as MBL são capazes de hidrolisar todos os antimicrobianos $\beta$-lactâmicos, exceto monobactâmicos e não são inibidas por ácido clavulânico, sulbactam e tazobactam (PFEIFER et al., 2010).

Carbapenêmicos normalmente podem ser usados no tratamento de infecções causadas por bactérias produtoras de $\mathrm{AmpC}$, mas a resistência a carbapenêmicos pode surgir em alguns microrganismos devido a mutações que ocasionam a perda de porina da membrana externa ou ativação da bomba de efluxo (JACOBY, 2009).

No presente estudo, apenas um isolado de E.coli foi positivo para a produção de MBL. Foram pesquisados os genes $b l a_{\mathrm{IMP}}, b l a \mathrm{v}_{\mathrm{IM}}$ e $b l a_{\mathrm{SPM}-1}$ e nenhum dos genes foram detectados. Pode ser que esse isolado possua outros genes de resistência os quais não pesquisamos. 


\section{CONCLUSÕES}

Com base nos resultados encontrados pode-se concluir que:

- O grupo filogenético B1 foi o de maior frequência entre os isolados de $E$. coli de diversas fontes, sendo que o grupo A, B2 e D também foram identificados;

- O processo de tratamento da água não foi suficiente para eliminar bactérias patogênicas, pois estas pertenceram aos grupos B2 e D;

- Dentre os isolados estudados verificou-se baixa taxa de resistência aos antimicrobianos;

-Isolados de $E$. coli provenientes de água mineral podem ser resistentes a diversos beta-lactâmicos, bem como apresentarem produção de enzimas capazes de impedirem a ação do antimicrobiano, representando risco a Saúde Pública;

-Isolados de $E$. coli com perfil fenotípico de resistência a cefoxitina e/ ou cefotetan são decorrentes da hiperprodução de AmpC cromossômica. 


\section{REFERÊNCIAS}

Aarestrup FM. Veterinary drug usage and antimicrobial resistance in bacteria of animal origin. Basic Clin Pharmacol Toxicol. 2005; 96: 271-281.

Abongo'o BO, Momba MN, Mwambakana JN. Prevalence and antimicrobial susceptibility of $E$. coli $0157: \mathrm{H} 7$ in vegetables sold in the Amathole District, Eastern Cape Province of South Africa. J Food Prot. 2008; 17(4):816-819.

Abreu AG, Marques SG, Monteiro-Neto V, Carvalho RM, Gonçalves AG.Nosocomial infection and characterization of extended-spectrum $\beta$-lactamasesproducing Enterobacteriaceae in Northeast Brazil.Rev Soc Bras Med Trop. 2011; 44(4):441-446.

Afset JE, Anderssen E, Bruant G, Harel J, Wieler L, Bergh K. Phylogenetic backgrounds and virulence profiles of atypical Enteropathogenic Escherichia coli strains from a case-control study using multilocus sequence typing and DNA microarray analysis. J Clin Microbiol. 2008; 46(7): 2280-2290.

Ahmed AM, Shimabukuro H, Shimamoto T.Isolation and molecular characterization of multidrug-resistant strains of Escherichia coli and Salmonella from retail chicken meat in Japan. J Food Sci. 2009; 74(7):405-10.

Alexander TW, Inglis GD, Yanke LJ, Topp E, Read RR, Reuter T, Mcallister TA. Farm-to-fork characterization of Escherichia coli associated with feedlot cattle with known history of antimicrobial use. Int J Food Microbiol. 2010; 137(1):40-8. 
Allen HK, Donato J, Wang HH, Cloud-Hansen KA, Davies J, Handelsman J. Call of the wild? Antibiotic resistance genes in natural environments. Nature Revies. 2010; 8: 251-59.

Balsalobre LC. Pesquisa de genes codificadores de enterotoxinas e $\beta$-lactamases em Aeromonas jandaei e Aeromonas hydrophila provenientes de ambientes aquáticos [dissertação de mestrado]. São Paulo: Faculdade de Saúde Pública da USP; 2009.

Baquero F, Martinez JL, Canto R. Antibiotics and antibiotic resistance in water environments.Curr Opinion Biotechnol. 2008; 19: 260-265.

Bauernfeind A, Chong Y, Schweighart S. Extented broad spectrum beta-lactamase in Klebsiella pneumonia including resistance to cephamycins. Infecton. 1989; 17(5):316-321.

Bauernfeind A, Chong Y, Lee K. Plasmid-encoded AmpC $\beta$-lactamases: How far have we gone 10 years after the discovery? Yonsei Medical Journal. 1998; 39(6): 520-525.

Bengtsson S, Naseer U, Sundsfjord A, Kahlmeter G, Sundgvist M. Sequence types and plasmid carriage of uropathogenic Escherichia coli devoid of phenotypically detectable resistance. J Antimicrob Chemother. 2012; 67(1):69-73.

Berg RD. Bacterial translocation from the gastrointestinal tract. Trends Microbiol. $1995 ; 149-154$. 
Boehme S, Werner G, Klare I, Reissbrodt R, Wite W. Occurrence of antibioticresistant enterobacteria in agricultural foodstuffs. Mol Nutr Food Res. 2004; 48:522531.

Bonnet R. Growing group of extended-spectrum beta-lactamases: CTX-M enzymes. Antimicrob Agents Chemother. 2004; 48:1-14.

Borges LJ, Amorim LJM, Dantas MC, André PB, Campos MRH, Serafini AB. Qualidade microbiológica de empadão Goiano comercializado em uma feira de lazer de Goiânia/GO e teste de susceptibilidade antimicrobiano de isoladoss isoladas. Rev Patol Trop. 2008; 37(2): 131-142.

Bou G,Oliver A, Ojeda M, Monzon C, Martinez-Beltran J. Molecular Characterization of FOX-4, a new AmpC-type plasmid-mediated $\beta$-lactamase from an Escherichia coli strain isolated Spain.Antimicrobial Agents and Chemotherapy. 2000; 44(9): 2549-2553.

Bradford, PA. Extended-Spectrum $\beta$-Lacatamases in the 21 st Century: Characterization, Epidemiology, and Detection of This Important Resistance Threat. Clin Microbiol Rev. 2001; 14(4): 933-951.

BRASIL. Ministério da Saúde. Agência Nacional de Vigilância Sanitária. Resolução RDC $\mathrm{n}^{\circ} 12$ de 2 de janeiro de 2001. Regulamento técnico sobre padrões microbiológicos para alimentos e seus Anexos I e II. Diário Oficial [da] República Federativa do Brasil, Brasília, DF, jan.2001. Seção 1, p. 54. 
BRASIL. Conselho Nacional do Meio Ambiente. Resolução $n^{\circ} 274$ de 29 de novembro de 2000 .

Brooks GF, Carroll KC, Butel JS, Morse SA. Jawetz, Melnick e Adelberg Microbiologia Médica. Rio de Janeiro: McGraw Hill Interamericana do Brasil; 2009. Bacilos entéricos Gram - negativos (Enterobacteriaceae); p. 249-262.

Bush K, Jacoby GA, Medeiros AA. A functional classsification scheme for betalactamases and its correlation with molecular structure. Antimicrob Agents Chemother. $1995 ; 39: 1211-1233$.

Bush K, Jacoby GA. An Updated Functional Classification of $\beta$-Lactamases. Antimicrob Agents Chemother. 2010; 54(3):969-976.

Carlos C, Pires MM, Stoppe NC, Hachich EM, Sato MIZ, Goes TAT, Amaral LA, Ottoboni LMM. Escherichia coli phylogenetic group determination and its application in the identification of the major animal source of fecal contamination. BMC Microbiology. 2010; 10(161):1-10.

Castanheira M, Toleman MA, Jones RN,Schimidt FJ, Walsh TR. Molecular characterization of a beta-lactamase gene, blaGIM-1, encoding a new subclass of metallo-beta-lactamase.Antimicrob Agents Chemother. 2004; 48(12):4654-61.

Castanheira M. Caracterização de genes que codificam $\beta$-lactamases mediados por integrons de classe 1 em amostras de Pseudomonas aeruginosa. [tese de doutorado]. São Paulo: Universidade Federal de São Paulo. Escola Paulista de Medicina; 2005. 
Castanheira M, Pereira AS, Nicoletti AG, Pignatari AC, Barth AL, Gales Ac. First report of plasmid qnrA1 in a ciprofloxacin-resistant in Escherichia coli strain in Latin America. Antimicrob Agents Chemother. 2007; 51(4): 1527-9.

Cergole-Novella MC, Guth BE, Castanheira M, Carmo MS, Pignatari AC. First description of bla(CTX-M-14) and bla(CTX-M-15)- producing Escherichia coli isolates in Brazil. Microb Drug Resist. 2010; 16(3): 177-184.

Chagas TP, Seki LM, Cury JC, Oliveira JA, Dávila AM, Silva DM, Asensi MD.Multiresistance, beta-lactamase-encoding genes and bacterial diversity in hospital wastewater in Rio de Janeiro, Brazil. J Appl Microbiol. 2011; 111 (3):572581.

Chah KF, Oboegbulem SI. Extend-spectrum beta-lactamase production among ampicillin-resistant Escherichia coli strains from chicken in Enugu state, Nigeria. Braz J Microbiol. 2007; 38: 681-686.

Chapman PA, Ellin M, Ashton R, Shafique W. Comparison of culture, PCR and immunoassays for detecting Escherichia coli 0157 following enrichment culture and immunomagnetic separation performed on naturally contaminated raw meat products. Int J Food Microbiol. 2001; 68:11-20.

Clermont O, Bonacorsi S, Bingen E. Rapid and simple determination of the Escherichia coli phylogenetic group. Appl and Environ Microbiol.2000; 66(10): 4555-58. 
Clinical and Laboratory Standards Institute (CLSI). Performance Standards for Antimicrobial Susceptibility Testing; Eighteenth International Supplement. CLSI Publication M02-M07, v. 30, n 1. Wayne, PA: CLSI; 2019.

Clinical and Laboratory Standards Institute (CLSI). Performance Standards for Antimicrobial Susceptibility Testing; Twenty first Informational Supplement. CLSI Publication M100-S22, v. 30, nº 1. Wayne, PA: CLSI; 2012.

Cornaglia G, Giamarellou H, Rossolini GM. Metallo $\beta$-lactamase: a last frontier for b lactams? Lancet Infect Dis. 2011; 11(5):381-393.

Corvec S, Prodhomme A, Giraudeau C, Dauvergne S, Reynaud A, Caroff N. Most Esherichia coli strains overproducing chromosomal AmpC $\beta$-lactamase belong to phylogenetic group A. Journal of Antimicrobial Chemotherapy. 2007; 60: 872-876.

Coudron PE, Moland ES, Thomson KS. Occurrence and detection of AmpC betalactamases among Escherichia coli, Klebsiella pneumoniae, and Proteus mirabilis isolates at a veterans medical center. J Clin Microbiol. 2000; 38:1791-1796.

D'Alincourt Carvalho-Assef AP, Leão RS, da Silva RV, Ferreira AG, Seki LM, Asensi MD, Marques EA. Escherichia coli producing KPC-2 carbapenemase: first report in Brazil. Diagn Microbiol Infect Dis. 2010; 68(3): 337-8.

Dalmarco EM, Blatt SL, Córdova CMM. Identificação Laboratorial de $\beta$-Lactamases de Espectro Estendido (ESBLs)- Revisão. RBAC. 2006; 38(3): 171-177. 
Deshpande LM, Jones RN, Fritsche TR, Sader HS. Occurrence of plasmidic Ampc type $\beta$-lactamase-mediated resistance in Escherichia coli: report from the SENTRY Antimicrobial Surveillance Program (North America,2004). International Journal Antimicrobial Agents. 2006; 28: 578-581.

Doi Y, Paterson DL. Detection of plasmid-mediated class C $\beta$-lactamases. I J Infect Dis. 2007; 11: 191-197.

Dropa, M. Caracterização genotípica de isoladoss da família Enterobacteriaceae produtoras de $\beta$-lactamases de espectro estendido, isoladas de pacientes de um hospital da rede pública da cidade de São Paulo [dissertação de mestrado]. São Paulo: Faculdade de Saúde Pública da USP; 2006.

Dropa, M, Balsalobre L, Lincopan N, Matté G, Matté MH. High diversity of extendspectrum beta-lactamase genes among Enterobacteriaceae isolated in a university hospital in Brazil. Clin Microbiol Infect. 2011. Submitted.

Duriez P, Clermont $\mathrm{O}$, Bonacorsi S, Bingen E, Chaventré A, Elion J, Picard B, Denamur E. Commensal Escherichia coli isolates are phylogenetically distributed among geographically distinct human populations. Microbiology. 2001; 147: 167176.

Egea P, Lopez-Cerero L, Navarro MD, Rodriguez-Bano J, Pascual A. Assessment of the presence of extended -spectrum beta-lactamase-producing Escherichia coli in eggshells and ready-to-eat products. Eur J Clin Microbiol Infect Dis. 2011; 30(9):1045-1047. 
Farmer III JJ, Boatwright KD, Janda M. Enterobacteriaceae: Introduction and identification. In: Murray PR, Baron EJ, Jorgensen JH, Landry ML, Pfaller MA. Manual of Clinical Microbiology. $9^{\circ}$ ed. American Society for Microbiol: Washington, 2007.p. 649-669.

Figueira V, Serra E, Manaia CM. Differential patterns of antimicrobial resistance in population subsets of Escherichia coli isolated from waste- and surface waters. Sci Total Environ. 2011; 409(6):1017-23.

Forward KR, Willey BM, Low DE, McGeer A, Kapala MA, Kapala MM, Burrows LL. Molecular mechanisms of cefoxitin resistance in Escherichia coli from the Toronto area hospitals. Diagnostic/microbiology and Infectious Disease. 2001; 41: 57-63.

Frost LS, Leplae R, Summers A, Toussaint A. Mobile genetic elements: the agents of open source evolution. Nature Reviews. 2005; 3:722-732.

Giradeau JP, Dalmasso A, Bertin Y, Ducrot C, Bord S, Livrelli V, Vernozy-Rozand C, Martin C. Asssociation of virulence genotype with phylogenetic background in comparison to different seropathotypes of Shiga Toxin - Producing Escherichia coli isolates. J Clin Microbiol. 2005; 43(12): 6098-6107.

Gousia P, Economou V, Sakkas H, Leveidiotou S, Papadopoulou C. Antimicrobial resistance of major foodborne pathogens from major meats products. Foodborne Pathog Dis. 2011; 8(1):27-38. 
Gulmez D, Woodford N, Palepou MF, Mushtaq S, Metan G, Yakupogullari Y, Kocagoz S, Uzun O, Hascelik G, Livermore DM. Carbapenem-resistant Escherichia coli and Klebsiella pneumioniae isolates from Turkey with OXA-48-like carbapenemases and outer membrane protein loss.Int JAntimicrob Agents. 2008; 31(6):523-526.

Hammad AM, Ishida Y, Shimamoto T. Prevalence and molecular characterization of ampicillin-resistant Enterobacteriaceae isolated from traditional Egyptian Domiati cheese. Journal of Food Protection. 2009; 72(3): 624-630.

Hamelin K, Bruant G, El-Shaarawi A, Hill S, Edge TA, Fairbrother J, Harel J, Maynard C, Masson L, Brousseau R. ccurrence of virulence and antimicrobial resistance genes in Escherichia coli isolates from different aquatic ecosystems within the St. Clair River and Detroit Rive. Appl Environ Microbiol. 2007; 73(2):477-84.

Hentschke M, Kotsakis SD, Wolters M, Heisiq P, Miriaqou V, Aepfelbacher M.CMY-42,a novel plasmid-mediated CMY-2 variant AmpC beta-lactamase. Microb Drug Resist. 2011; 17(2):165-9.

Hopkins KL, Batchelor MJ, Liebana E, Deheer-Graham AP, Threlfall EJ. Characterisation of CTX-M and AmpC genes in human isolates of Escherichia coli identified between 1995 and 2003 in England and Wales. Int J Antimicrob Agents. 2006; 28: 180-192. 
Hussain M, Hasan F, Shah AA, Hameed A, Jung M, Rayamajhi N, Cha SB, Yoo HS. Prevalence of class A and AmpC- $\beta$-lactamases in clinical Escherichia coli isolates from Pakistan Institute of Medical Science, Islamabad, Pakistan. Jpn J Infect Dis. $2011 ; 64(3): 249-52$.

Ito CA, Gales AC, Toqnim MC, Munerato P, Dalla Costa LM.Quinolone-resistant Escherichia coli. Braz J Infect Dis. 2008;12(1)5-9.

Jacoby GA. AmpC $\beta$-Lactamases. Clin Microbiol Rev. 2009; 22(1): 161-182.

Kaper JB, Nataro JP, Mobley HLT. Pathogenic Escherichia coli. Nature Reviews. $2004 ; 2: 123-140$.

Koneman EW, Allen SD, Janda WM, Schreckenberger PC, Winn Jr WC. Diagnóstico microbiológico: texto e Atlas colorido. 5. ed. Rio de Janeiro: Medsi; 2001.

Koo HJ, Woo GJ. Distribution and transferability of tetracycline resistance determinants in Escherichia coli isolated from meat and meat products. Int J Food Microbiol. 2011.

Kümmerer $\mathrm{K}$, Significance of antibiotics in the environment. $\mathrm{J}$ Antimicrob Chemother. 2003; 1-3.

Lahey clinic. [acesso em 08 fev 2012]. Disponível em http://www.lahey.org/studies. 
Lamikanra A, CroweJL, Lijek RS,Odetoyin BW, Wain J,AboderinAQ, Okeke IN.Rapis evolution of fluoroquinolone-resistant Escherichia coli in Nigeria is temporally associated with fluoroquinolone use. BMC Infect Dis. 2011; 7(1):312.

Lee K, Yum JH, Yong D, Lee HM, Kim HD. Novel acquired metallo-bea-lactamase gene, bla (SIM-1), in a class 1 integron from Acinetobacter baumannii clinical isolates from Korea. Antimicrob Agents Chemother.2005;49(11):4485-91.

Lima-Bittencourt CI, Cursino L, Gonçalves-Dornelas H, Pontes DS, Nardi RMD, Callisto M, Chartone-Souza E, Nascimento AMA. Multiple antimicrobial resistance in Enterobacteriaceae isolates from pristine freshwater. Genetics and molecular research. $2007 ; 6(3): 510-521$.

Livermore DM. $\beta$-lactamase in laboratory and clinical resistance. Clin Microbiol Rev. 1995; 8(4):557-584.

Luo Y, Cui S, Li J, Lin L, Hu C, Jin S, Ye L, Zhao Q, Ma Y. Characterization of Escherichia coli isolates from healthy food handlers in hospital. Microb Drug Resist. 2011; Microb Drug Resist. 17(3):443-448.

Machado E, Coque TM, Cantón R, Sousa JC, Peixe L.Antibiotic resistance integrons and extended-spectrum (beta) - lactamases among Enterobacteriaceae isolates recoverd from chickens and swine in Portugal. J Antimicrob Chemother. 2008; 62(2):296-32.

Martinez MB, Trabulsi LR.Enterobactriaceae. In: Trabulsi LR, Alterthum F. Microbiologia. Atheneu; 2008.271-280 
Mataseje LF, Neumann N, Crago B, Baudry P, Zhanel GG, Louie M, Mulvey MR.Characterization of cefoxitin-resistant Escherichia coli isolates from recreactional beaches and private drinking water in Canada between 2004 and 2006. Antimicrob Agents Chemother. 2009; 53(7):3126-30.

Mendes RE. Caracterização dos elementos genéticos móveis responsáveis pela disseminação de genes associados à resistência bacteriana em Pseudomonas spp. isoladas na América Latina. [tese de doutorado]. São Paulo: Universidade Federal de São Paulo. Escola Paulista de Medicina; 2005.

Mendes RE, Castanheira M, Pignatari ACC, Gales AC. Metalo- $\beta$-lactamases. J Bras Patol Med Lab. 2006; 42(2): 103-113.

Menezes EA, Alves EGB, Cunha FA, Ângelo MRF, Salviano MRC, Oliveira IRN. Avaliação do ertapenem frente a bacilos gram negativos produtores de enzima beta lactamase de espectro expandido (ESBL). RBAC. 2007; 39(3): 189-191.

Menezes KMP, Góis GA, Oliveira ID, Pinheiro MS, Brito AMG. Avaliação da resistência a da Escherichia coli frente a Ciprofloxacina em uroculturas de três laboratórios clínicos de Aracaju-SE. RBCA. 2009; 41(3): 239-242.

Molina-López J, Aparicio-Ozores G, Ribas-Aparicio RM, Gavilanes-Parra S, Chávez-Berrocal ME, Hernandez-Castro R, Manjarrez-Hernandez HA.Drug Resistance, serotypes, and phylogenentic groups among uropathogenic Escherichia coli including O25-ST131 in Mexico city. J Infect Dev Ctries. 2011; 5(12):840-849 
Moura EMM. Análise do perfil de resistência a antibióticos e detecção dos genes de virulência e resistência em Aeromonas provenientes de amostras ambientais. [dissertação de mestrado]. São Paulo: Faculdade de Saúde Pública da USP; 2010.

Ministério da Saúde. Portaria $n^{\circ} 2914$, de 12 de dezembro de 2011. Estabelece os procedimentos e responsabilidades relativos ao controle e vigilância da qualidade da água para o consumo humano e seu padrão de potabilidade e dá outras providências. Diário Oficial da União. $13 \mathrm{dez} 2011$; Seção 1.

Montelli AC, Sadatsune T. Antibioticoterapia para o clínico. Soc Bras Microbiol. Rio de Janeiro, p.7, 2001.

Moreira MAS, Ferreira AB, Trindade TFSL, Reis ALO, Moraes CA. Resistência a antimicrobianos dependente do sistema de efluxo multidrogas em Escherichia coli isoladas de leite mastítico. Arq Bras Med Vet Zootec. 2008; 60 (6): 1307-1314.

Naseer U, Haldorsen B, Simonsen GS, Sundsfjord A. Sporadic occurrence of CMY2-producing multidrug-resistant Escherichia coli of ST-complexes 38 and 448, and ST 131 in Norway. Clin Microbiol Infect. 2009; 16: 171-178.

Nataro JP, KaperJB. Diarrheagenic Escherichia coli.Clin Microbiol Rev.1998;142201.

Oliveira CF, Forno NLFD, Alves IA, Horta JA, Rieger A, Alves SH. Prevalência das famílias TEM, SHV e CTX-M de $\beta$-lactamases de espectro estendido em Escherichia coli e Klebsiella spp no hospital unversitário de Santa Maria, Estado do Rio Grande do Sul. Rev Socied Bras Med Trop. 2009; 42 (5): 556-60. 
Orsi RH, Stoppe NC, Sato MIZ, Ottoboni LMM. Identification of Escherichia coli from groups A, B1, B2 and D in drinking water in Brazil. J of Water and Health. 2007; 5(2): 323-27.

Orsi RH, Stoppe NC, Sato MIZ, Prado PI, Ottoboni LMM. Phylogenetic group distribution among Escherichia coli isolated from rivers in São Paulo state, Brazil. World J Microbiol Biotech. 2008; 24: 2573-1577.

Paneto BR, Schocken- Iturrino RP, Macedo C, Santo E, Marin JM. Occurrence of toxigenic Escherichia coli in raw milk cheese in Brazil. Arq Bras Med Vet Zootec. 2007; 59(2): 508-12.

Paterson DL.Resistance in gram-negative bacteria: Enterobacteriaceae.Am J Infect Control.2006; 34:20-28.

Pavez M, Neves P, Dropa M, Matté MH, Grinbaum RS, Araújo MR, Mamizuka E, Lincopan N. Emergence of carbapenem -resistant Escherichia coli producing CMY2-type AmpC $\beta$-lactamase in Brazil. J Med Microbiol. 2008; 57: 1590-92.

Pedro SCM. Determinação de grupos filogenéticos e pesquisa de genes de virulência em cepas de Escherichia coli obtidos de amostras de queijo Minas. [ dissertação de mestrado]. São Paulo: Faculdade de Saúde Pública da USP; 2009.

Pérez-Pérez FJ, Hanson ND.Detection of plasmid-mediated AmpC beta-lactamase genes in clinical isolates by using multiplex PCR. J Clin Microbiol. 2002; 40(6): 2153-2162. 
Pfeifer Yvonne, Cullik A, Witte W. Resistance to cephalosporins and carbapenems in Gram-negative bacterial pathogens. International Journal of Medical Microbiology. 2010; 300: 371-379.

Picard B, Garcia JS, Gouriou S, Duriez P, Brahimi N, Bingen E, Elion J, Denamur E. The link between phylogenetic and virulence in Escherichia coli extraintestinal infection. Infect Immun. 1999; 67: 546-553.

Pitout JDD. Multiresistant Enterobacteriaceae: new threat of an old problem. Expert Review of Anti-infective Therapy.2008; 6(5):657-669.

Poirel L,Rodriguez-Martinez JM,Al Naiemi N, Debets-Ossenkopp YJ,Nordmann P. Characterization of DIM-1, an integron-encoded metallo-beta-lactamase from a Pseudomonas stutzeri isolate in the Netherkands.Antimicrob Agents Chemother. $2010 ; 54(6): 2420-4$.

Queenan AM, Bush K. Carbapenemases: the versatile beta-lactamases. Clin Microbiol Rev. 2007; 20(3):440-458.

Robins-Browne RM, Hartland EL. Escherichia coli as a cause of diarrhea. J Gastroenterol Hepatol. 2002; 17(4):467-475.

Rosengren LB, Waldner CL, Reid -Smith RJ. Associations between antimicrobial resistance phenotypes, antimicrobial resistance genes, and virulence genes of fecal Escherichia coli isolates from healthy grow-finish pigs.Appl Environ Microbiol.2009; 75(5):13731380. 
Rossi F. The challenges of antimicrobial resistance in Brazil. Antimicrobial Resistance. 2011 ; 52:1138-1143.

Ryu SH, Park SG, Choi SM, Hwang YO, Ham HJ, Kim SU, Lee YK, Kim MS, Park GY, Kim KS, Chae YZ.Antimicrobial resistance and resistance genes in Escherichia coli strains isolated from commercial fish and seafood.Int J Food Microbiol.2012; 3152:14-18.

Sabaté M, Prats G, Moreno E, Ballesté E, Blanch AR, Andreu A. Virulence and antimicrobial resistance profiles among Escherichia coli strains isolated from human and animal wastewater. Research in Microbiol. 2008; 159: 288-293.

Sader HS, Gales AC, Pfaller MA, Mendes RE, Zoccoli C, Barth A, Jones RN. Pathogen frequency and resitance patterns in Brazilian hospitals: summary of results from three years of the SENTRY Antimicrobial Surveillance Program. Braz J Infect Dis.2001; 5(4):20-214.

Saleh I, Zouhairi O, Alwan N, Hawi A, Barbour G, Harakeh S.Antimicrobial resistance and pathogenecity of $\mathrm{E}$. coli isolated frim common dairy products in the Lebanon.Ann Trop Med Parasitol. 2009; 103(1):39-52.

Scheutz F, Strockbine NA. Genus I Escherichia. In: Brenner DJ, Krieg NR, Staley JT. editores, Garrity GM, editor chefe. Bergey's Manual of Systematic Bacteriology. 2. ed. New York: Springer; 2005. v. 2, p.607-624. 
Sekiguchi J, Motita K, KitaoT. KHM-1, a novel plasmid-mediated metello-betalactamase from a Citrobacter freundii clinical isolates. Antimicrob Agents Chemother.2008; 52(11):4194-7.

Sidjabat HE, Paterson DL, Qureshi ZA, Adams-Haduch JM, Keefe A, Pascua A, Rodriguez-Baño, Doi Y. Clinical features and molecular epidemiology of CMYType- $\beta$-lactamase- producing Escherichia coli. Clin Infect Dis. 2009; 48(6): 739744.

Silva-Dias RC, Borges-Neto AA, D’Almeida FGI, De-Oliveira MP, Riley LW, Moreira BM. Prevalence of AmpC and other beta-lactamases in enterobacteria at a large urban university hospital in Brazil. Diagn Microbiol Infect Dis.2008; 60(1): 7987.

Singtohin S, Chanawong A, Lulitanond A, Sribenjalux P, Anuncharoen A, Kaewkes W, Songsri J, Pienthaweechai. CMY-2, CMY-8bb, and DHA-1 plasmid-mediated AmpC $\beta$-lactamases among clinical isolates of Escherichia coli and Klebsiella pneumoniae from a university hospital, Thailand. Diag Microbiol Infect Dis. In press. 2010 .

Tausova D, Dolejska M, Cizek A, Hanusova L, Hrusakova J, Svoboda O, Camlik G, Literak I. Escherichia coli with extended-spectrum-beta-lactamase and plasmidmediated quinolone resistance genes in great cormorants and mallards in central Europe. J Antimicrob Chemother. 2012; 67(5):1103-7. 
Tavares W. Antibióticos e quimioterápicos para o clínico. São Paulo: Atheneu; 2009 a. Classificação dos antibióticos; p. 11-16.

Tavares W. Antibióticos e quimioterápicos para o clínico. São Paulo: Atheneu; 2009 b. Mecanismos de ação dos antimicrobianos; p. 23-36.

Tavares W. Antibióticos e quimioterápicos para o clínico. São Paulo: Atheneu; 2009c. Resistencia Bacteriana; p. 37-54.

Tavares W. Antibióticos e quimioterápicos para o clínico. São Paulo: Atheneu; 2009 d. Teste de sensibilidade in vitro; p. 17-22.

Tenaillon O, Skurnik D, Picard B, Denamur E. The population genetics of commensal Escherichia coli. Nature reviews. 2010; 8:207-217.

Tenover FC. Mechanisms of antimicrobial resistance in bacteria. The American Journal of Medicine. 2006; 119 (6A): S3-S10.

Thomson KS. Extended-Spectrum- $\beta$-Lactamase, AmpC, and Carbapenemase Issues. J Clin Microbiol. 2010; 48(4): 1019-1025.

Tiba MR, Nogueira GP, Leite DS. Estudo dos fatores de virulência associados à formação de biofilme e agrupamento filogenético em Escherichia coli isoladas de pacientes com cistite. Rev Socied Bras Med Trop. 2009; 42(1): 58-62.

Toleman MA, Simm AM, Murphy TA, Gales AC, Biedenbach DJ, Jones RN, Walsh TR. Molecular characterization of SPM-1, a novel metallo- $\beta$-lactamase isolated in 
Latin America: report from the SENTRY antimicrobial surveillance programme. J Antimicrob Chemother. 2002; 50:673-679.

Vieira JMS, Saraiva RMC, Mendonça LCV, Fernandes VO, Pinto MRC, Vieira ABR. Susceptibilidade antimicrobiana de bactérias isoladas de infecções do trato urinário de pacientes atendidos no hospital universitário Bettina Ferro de Souza, Belém- PA. RBAC. 2007; 39(2): 119-121.

Vieira RHSF, Atayde MA, Carvalho EMR, Carvalho FCT, Fonteles AA. Contaminação fecal das ostras Crassostrea rhizophorae e da água de cultivo do estuário do Rio Pacoti (Eusébio, Estado do Ceará): isolamento e identificação de Escherichia coli e sua susceptibilidade a diferentes antimicrobianos. Braz J Vet Res Anim Scic. 2008; 45(3): 180-189.

Vignaroli C, Luna MG, Rinaldi C, Di Cesare A, Danovaro R, Biavasco F. New sequence types and multidrug resistance among pathogenic Escherichia coli isolates from coastal marine sediments. Applied and Environmental Microb. 2012; 78(1): 3916-3922.

Yong D, Bell JM, Ritchie B, Pratt R, Toleman MA, Walsh TR. A novel sub-group metallo-beta-lactamase (MBL), AIM-1 emerges in Pseudomonas aeruginosa (PSA) from Australian $.47^{\text {th }}$ Interscience Conference on Antimicrobial Agents and Chemotherapy; Chicago, USA; sept17-20, 2007.C1-1417.

Yong D, Toleman MA, Giske CG, Cho HS, Sundman K, Lee K, Walsh TR.Characterization of a new metallo-beta-lactamase gene, bla (NDM-1), and a 
erythromycin esterase gene carried on a unique genetic structurein Klebsiella pneumoniae sequence type 14 from India .Antimicrob Agents Chemother. 2009; 53(12):5046-5054.

Wachino J. Yoshida H, Yamane K, Suzuki S,Matsui M.SMB-1, a novel subclass B3 metallo-beta-lactamase, associated with ISCR1 and a Class 1 integron, from a carbapenem-resistant Serratia marcescens clinical isolate. Antimicrob Agents Chemother.2011; 55(11): 5143-9.

Walther-Rasmussen J, Hoiby N. Class A carbapenemases. J Antimicrob Chemother. $2007 ; 60(3): 470-482$.

Wang HH, Manuzon M, Lehman M, Wan k, Luo H, Wittum TE, Yousef A, Bakaletz L. Food commensal microbes as a potentially important avenue in transmitting antibiotic resistance genes. FEMS Microbiol Lett. 2006; 254: 226-231.

Weldhagen GF, Poirel L, Nordmann P. Ambler class A extended-spectrum $\beta$ lactamases in Pseudomonas aeruginosa: novel developments and clinical impact.Antimicrob Agents Chemother. 2003; 47(8):2385-2392.

Witte W. Medical consequences of antibiotic use in agriculture. Science.1998; 279: 996-997.

Zanella GN, Mikcha JMG, Bando E, siqueira VLD, Machinskim M.Occurrence and antibiotic resistance of coliform bactéria and antimicrobial residues in pasteurized cow's milk from Brazil. J Food Prot. 2010; 73(9):1684-1687. 
Zavascki AP, Gaspareto PB, Martins AF, Gonçalves AL, Barth AL. Outbreak of carbapenem-resistant Pseudomonas aeruginosa producing SPM-1 metallo- $\beta$ lactamase in a teaching hospital in southern Brazil. J Antimicrob Chemother. 2005; 56(6): 1148-11 